University of Wollongong

Research Online

Faculty of Engineering and Information

Faculty of Engineering and Information

Sciences - Papers: Part B

Sciences

2017

\title{
Microbial fuel cell is emerging as a versatile technology: a review on its possible applications, challenges and strategies to improve the performances
}

\author{
Ravinder Kumar \\ Universiti Malaysia Pahang \\ Lakhveer Singh \\ Universiti Malaysia Pahang \\ A W. Zularisam \\ Universiti Malaysia Pahang \\ Faisal I. Hai \\ University of Wollongong, faisal@uow.edu.au
}

Follow this and additional works at: https://ro.uow.edu.au/eispapers1

Part of the Engineering Commons, and the Science and Technology Studies Commons

Research Online is the open access institutional repository for the University of Wollongong. For further information contact the UOW Library: research-pubs@uow.edu.au 


\title{
Microbial fuel cell is emerging as a versatile technology: a review on its possible applications, challenges and strategies to improve the performances
}

\author{
Abstract \\ Microbial fuel cells (MFCs) are emerging as a versatile renewable energy technology. This is particularly \\ because of themultidimensional applications of this eco-friendly technology. The technology depends on \\ the electroactive bacteria,popularly known as exoelectrogens, to simultaneously produce electric power \\ and treat wastewater. Electrodemodifications with nanomaterials such as gold nanoparticles and iron \\ oxide nanoparticles or pretreatment methods suchas sonication and autoclave sterilization have shown \\ promising results in enhancing MFC performance for electricitygeneration and wastewater treatment. The \\ MFC technology has been also investigated for the removal of various heavymetals and toxic elements, \\ and to detect the presence of toxic elements in wastewater. In addition, the MFCs can bemodified into \\ microbial electrolysis cells to generate hydrogen energy from various organic matters. This article \\ providesa comprehensive and state-of-the-art review of possible applications of the MFC technology. This \\ also points out thevarious challenges that limit MFC performance. Finally, this article identi fies the \\ strategies to improve MFC performancefor different applications.

\section{Disciplines} \\ Engineering | Science and Technology Studies

\section{Publication Details} \\ Kumar, R., Singh, L., Zularisam, A. W. \& Hai, F. I. (2017). Microbial fuel cell is emerging as a versatile \\ technology: a review on its possible applications, challenges and strategies to improve the performances. \\ International Journal of Energy Research, Online First 1-26.
}




\title{
Microbial fuel cell is emerging as a versatile technology: A review on its
} possible applications, challenges, and strategies to improve the

\section{performances}

\author{
Ravinder Kumar ${ }^{\mathrm{a}}$, Lakhveer Singh ${ }^{*, a}$, A.W. Zularisam ${ }^{\mathrm{a}}$, Faisal I. Hai ${ }^{\mathrm{b}}$ \\ ${ }^{a}$ Faculty of Engineering Technology, Universiti Malaysia Pahang, Lebuhraya Tun Razak, \\ 26300 Gambang, Kuantan, Pahang, Malaysia \\ ${ }^{\mathrm{b}}$ Strategic Water Infrastructure Laboratory, School of Civil, Mining and Environmental \\ Engineering, University of Wollongong, NSW 2522, Australia \\ Corresponding author: lakhveer@ump.edu.my, lucki.chem09@gmail.com
}

\section{SUMMARY}

Microbial fuel cells are emerging as a versatile renewable energy technology. This is particularly because of the multidimensional applications of this eco-friendly technology. The technology depends on the electroactive bacteria, popularly known as exoelectrogens to simultaneously produce electric power and treat wastewater. The electrode modifications with nanomaterials such as gold nanoparticles, iron oxide nanoparticles or pre-treatment methods such as sonication and autoclave sterilization have shown promising results to enhance the MFC performance for electricity generation and wastewater treatment. The MFC technology has been also investigated for the removal of various heavy metals and toxic elements, and to detect the presence of toxic elements in wastewater. In addition, the MFCs can be modified into microbial electrolysis cells to generate hydrogen energy from various organic matter. This article provides a comprehensive and state-of-the-art review of possible 
1 applications of the MFC technology. This also points out the various challenges that limit the

2 MFC performance. Finally, this article identifies the strategies to improve MFC performance

3 for different applications.

4 KEYWORDS: microbial fuel cell; electricity generation; wastewater treatment;

5 bioremediation; biosensor; hydrogen production

\section{1. INTRODUCTION}

7 Depletion of non-renewable energy resources and environmental pollution are critical threats

8 facing us. Extracting energy from organic or inorganic wastes can provide an efficient means

9 to solve the energy and environmental problems simultaneously. Many anaerobic

10 fermentation technologies have been combined with other purification techniques to generate

11 alternative energy fuels such as hydrogen and methane [1-3]. However, a sustainable energy

12 collection must include a diversity of carbon-neutral and renewable energy technologies.

13 Microbial fuel cell (MFC) technology has attracted an increased number of researchers in the recent years due to its potential particularly for bioenergy production and wastewater treatment. This is reflected by the number of articles published in last five years that has increased successively from year to year, as shown in Fig. 1. MFC technology has become an attractive technology today because of its capability to convert the chemical energy present in organic/inorganic wastes into electrical energy. It links microbial metabolism with electrochemical reactions [3-5]. Consequently, the technology can be used for electricity generation, wastewater treatment, bioremediation of heavy metals/toxic compounds and other niche applications. The general principle of an MFC is given in Fig. 2. MFCs are the bioelectrochemical devices that typically consist of two chambers i.e. the anode chamber (anaerobic; contains an electrode, microorganisms and anolyte) and the cathode chamber (aerobic/anaerobic; an electrode, electron acceptor and a catalyst), separated by a proton 
1 exchange membrane (PEM) e.g., nafion [6-8]. The microorganisms are used as the

2 biocatalysts to oxidize the substrate in the anode chamber, and have been denoted as the 3 power house of MFCs. The electrons are transferred to the anodic (an electrode) surface, 4 which are then directed to the cathode through an electrical connection $[9,10]$. In the 5 cathode, the electrons combine with protons and oxygen to form water. A catalyst e.g., 6 platinum is generally used to catalyse the reduction reaction in the cathode; alternatively, a 7 microorganism can also be used to replace such costly catalyst $[11,12]$.

The advantage of MFCs mainly lies in the use of microorganisms as the biocatalysts at the anode and the cathode chambers of MFCs. The exceptional characteristic of the microorganisms used in MFCs is their self-potential to mediate the electrons (generated from the oxidation of the substrates) from their outer cell membrane to the surface of an electrode (in anode) and to accept the electrons from the electrode surface (in cathode) to catalyse the reduction of electron acceptors e.g., oxygen reduction $[5,9,12]$. The microorganisms that contain a molecular machinery to transfer the electrons to an electron acceptor without any external assistance or to accept the electrons from the electrode surfaces are usually called as exoelectrogens. Due to this unique characteristic of exoelectrogens the MFC technology has been experimented for a number of applications. The most widely studied application of MFC technology is electricity generation. In the anode chamber of an MFC, the oxidation of organic matter by exoelectrogens results into a low redox potential while in the cathode chamber, reduction of an electron acceptor e.g., oxygen results into a higher redox potential. This difference in the redox potentials drives the electrons to flow from the anode to the cathode, which consequently results in bioelectricity generation. Many different designs have been utilized to produce electric current in various optimized parameters [10-12]. A pure culture (e.g., G. sulfurreducens and Shewanella oneidensis) or a mixed culture (from 
1 anaerobic sludge or primary wastewater) can be used to generate electric current [13-18].

2 Many attempts have been made to increase the electric output in MFCs. Out of these, anode surface modifications with nanomaterials and bacterial gene modification are the most prevalent approaches that have been employed to improve the MFC performances [19-21, 22]. For example, nitrogen doped carbon nanoparticles were coated on carbon cloth electrodes, which increased the power density more than three times as compared to untreated electrodes [21]. Alternatively, a synthetic flavin biosynthesis pathway from Bacillus subtilis was expressed in S. oneidensis MR-1, which secreted a very high amount of flavins than the wild type, consequently, increasing the power output $\sim 13$ folds as compared to wild $S$. oneidensis [22]. Because bacteria can degrade the organic matter present in the wastewater, the technology can be used to remove the pollutants and generate electricity from wastewater. Several wastewaters ranging from low-strength to high-strength have been utilized in MFCs for their treatment and electricity generation simultaneously [23-28, 29-34]. In addition, MFC can be modified into microbial electrolysis cell (MEC) to produce hydrogen gas, but unlike MFC, electricity is provided in the MEC to produce hydrogen [35]. Generally, a voltage of 0.2 to $0.8 \mathrm{~V}$ is required to reduce the protons to form hydrogen [10]. Such low voltage is easily achievable in the MFC. Therefore, an MFC can be used to supply the voltage to the MEC for hydrogen production.

The aim of this review article is to critically analyse the routes of MFC applications and the strategies to improve their performances. Many review articles have been published describing specific aspects of the MFCs such as the substrates used in MFCs [3], assessment of MFC configurations [1], and specific application of MFCs like wastewater treatment [4], and bioremediation [6]. However, that the current review provides a comprehensive understanding of the MFC applications, their basic principles, challenges and the strategies to 
improve their performances. The primary applications of MFCs i.e., electricity generation, wastewater treatment, bioremediation, biosensors, and hydrogen production have been covered. A special focus has been given to the strategies to improve the MFC performance, making the technology scalable in the real world to compete with commercialized green energy technologies.

\section{THE 'MOLECULAR MACHINERY' OF EXOELECTROGENS}

It is important to get an idea about the unique characteristic of MFC technology because of which this technology has become the centre of attraction among the renewable technologies. All the applications of MFC technology are particularly interesting because of the molecular machinery of the bacteria that helps in transferring the electrons to an electrode surface and vice-versa. The molecular machinery means the biomolecules, proteins or the genes that help to donate or accept the electrons between bacterial and electrode interface, which chiefly lies between the inner and the outer membrane of the bacteria. So far, only two bacteria namely, Geobacter spp. and Shewanella spp. have been extensively investigated to explore the extracellular electron transfer (EET) mechanisms. Two types of EET mechanisms have been confirmed in both the bacteria [5]. The first is direct electron transfer (DET) mechanism and the second is mediated electron transfer (MET) mechanism. The molecular machinery comprising the known pathways and hypothetical pathways is presented in Fig. 3.

G. sulfurreducens is the most studied and explored exoelectrogen in MFCs. It forms highly thick biofilms on the electrode surfaces and can utilize the various carbon sources as a substrate for bioenergy production. It has been found that G. sulfurreducens in its initial stages of biofilm formation relies on MET for electron transport. The exoelectrogen secretes flavin molecules such as riboflavin in the single layer biofilms. The riboflavin combines with outer membrane c-type cytochromes (OM c-Cyts) to make a complex that furthers the 
1 electron transfer to the electrode surface [5,22]. As the biofilm grows

2 G. sulfurreducens adapts to DET for extracellular electron transport. In a multi-layered 3 biofilm, G. sulfurreducens active adjacent to electrode surface utilizes OM c-Cyts (essentially

4 OmcZ) for extracellular electron transfer while the bacteria respiring distant from the 5 electrode produce conductive nanowires (type IV pili) that assist in transporting the electrons 6 inside the biofilm and finally onto the electrode surface [5].

7

The other exoelectrogen studied extensively for MFC applications is Shewanella oneidensis. The bacterium is the most versatile exoelectrogen in the MFCs because it exhibits the potential to reduce a variety of electron acceptors [36, 37]. Earlier S. oneidensis MR-1 was thought to produce conductive nanowires like type IV pili of G. sulfurreducens. But it is now confirmed that S. oneidensis does not contain nanowires and these nanowires like structures are the extensions of periplasmic and outer membrane multiheme cytochromes associated with outer membrane vesicles [38]. This exoelectrogen secretes mainly two types of flavin molecules. The first is riboflavin (RF) and the second is flavin mononucleotide (FMN). These flavin molecules act as cofactors for the cytochromes such as OmcA and MtrC. It has been found that RF acts as a cofactor for OmcA while FMN contains the binding sites for MtrC. [39]. These complexes, RF-OmcA and FMN-MtrC further promote the electron transfer to the electrode surfaces [39]. The various known proteins or genes from different exoelectrogens involved in EET mechanisms are depicted in Fig. 3. To date, some proteins or genes are well known to participate in EET mechanisms that function in a specific pathway. However, the functional role of other proteins/genes in EET mechanisms is still under debate and demands a deep investigation to validate their role and ability to mediate the electrons transfer. 
1

2

3

4

5

6

7

8

9

\section{MFCs FOR ELECTRICITY GENERATION}

The MFCs are chiefly used for the application of electric current generation and many efforts have been made to ameliorate the current density such as electrode modifications, MFCs designs, use of metal catalysts at the anode as well as at the cathode etc. $[1,6,8,9,12]$. Recent studies reporting high current densities even from reactors as small as $14 \mathrm{ml}$ are encouraging [2]. Evidently, Bruce E. Logan and his colleagues at The Pennsylvania State University, United States America (USA) successfully ran a small fan using an MFC with a working volume of two litres, (http://www.engr.psu.edu/mfccam/). If a two litre - MFC can run a small fan, then we can conceptually expect higher current output from an MFC of higher volume capacity e.g., of 2000 litres or even more. But it is unlikely to be materialized in the near future because of obstacles including very high cost of the materials used in MFCs (electrodes, PEM), high internal resistance, costly catalysts (e.g., platinum) used in cathode for oxygen reduction, and limited availability of exoelectrogens in the environment. However, researchers from all around the world continue to contribute to the technology to make it a viable alternative for renewable energy generation.

The first step in MFCs towards current generation is the acclimatization of the exoelectrogens in the anode chamber and subsequent biofilm formation on the electrode surface (anode). Consequently, the exoelectrogens form a conductive biofilm on the anode surface. The biofilm thickness may be a few tens of micrometre, for example, $\sim 30 \mu \mathrm{m}$ or $\sim 50$ $\mu \mathrm{m}[36,37]$. Biofilm formation by exoelectrogens is a unique characteristic and differs from other bacteria or microorganisms. The development of biofilm on the electrode surface from the single bacterial cell is stimulated by the assembly of adhesins and extracellular matrix components $[38,39]$. Later, some pivotal proteins specifically pili and outer membrane ctype cytochromes (OMC c-Cyts) e.g., OmcZ, OmcS etc. also promote the biofilm formation 
[40, 41]. Geobacter sulfurreducens is unable to form biofilm in the absence of pili and OMC c-Cyts [40]. The formation of thick biofilm is taken as an important parameter in MFCs for efficient performance. Usually, optimal biofilm thickness is preferred in MFCs for higher current densities, as highly thick biofilms also confine the electron passage [41]. In addition, the selection of suitable bacterial inoculum (pure culture of mixed culture) with preferred substrate can be highly beneficial to extract more energy for the current generation. For example, Geobacter sulfurreducens can reduce acetate with $\sim 100 \%$ electron recovery to generate electricity [42].

After the establishment of a suitable biofilm, the exoelectrogens transfer the metabolically generated electrons from their outer cell membrane to the anode surface. There are two known electron transfer mechanisms i.e. direct electron transfer (DET) and mediated electron transfer (MET), which have been observed in case of Geobacter species and Shewanella species [43-45]. In Geobacter sulfurreducens, DET involves OMC c-Cyts (e.g., OmcZ, OmcB) for the short-range electron transfer during the initial development of biofilms and pili (type IV) for long-range electron transfer in multilayer biofilms [17, 19]. In MET process flavin molecules such as riboflavin (RF) plays a key role in electron transfers [46]. In Shewanella oneidensis, the complex of cytochromes-flavins mediates the exocellular electron transfer mechanism. For example, flavin mononucleotide (FMN) acts as a cofactor for cytochrome MtrC and RF for cytochrome OmcA [47].

The transferred electrons on the anode surface are transported to the cathode surface via an electrical connection. The electrons at the cathode surface react with protons and an electron acceptor. If the electron acceptor is oxygen the end product will be water, resulting maximum open circuit voltage (OCV) at the cathode of ca. $0.805 \mathrm{~V}$. Generally, the cathode surface is bound with a catalyst to increase the oxygen reduction rate. The most commonly 
1 used catalyst is platinum [1]. The carbon/platinum electrodes are commercially available with

2 different concentrations of platinum e.g., carbon cloth with $0.2 \mathrm{mg} / \mathrm{cm}^{2}, 0.5 \mathrm{mg} / \mathrm{cm}^{2}$.

3 Alternatively, a microorganism can also be used for the oxygen reduction to make the fuel

4 cell more cost-effective. Electron acceptors other than oxygen, such as ferricyanide,

5 potassium permanganate are also useful alternatives [10].

7

The selection of exoelectrogens, substrate (electron donor), and the final electron acceptor are the pivotal factors in MFC technology. Different MFCs have used pure cultures as wells as mixed cultures for bioelectricity generation. Some examples of the MFC studies with pure cultures and mixed cultures are given in Table 1 and Table 2, respectively. The performance of similar MFCs with different inoculum can be compared to find which inoculum is more favourable to generate high power density. Some studies report that mixed cultures produce high power density than pure cultures [5]. However, a few other studies showed that pure cultures can also generate high current [40]. For example, in a continuous flow ministack MFC using carbon cloth for both the electrodes, fed with acetate, $G$. sulfurreducens produced higher power density than the mixed cultures using a similar reactor and operational conditions [40]. The study achieved a maximum power density of 1900 $\mathrm{mW} / \mathrm{m}^{2}$, which was approximately $21 \%$ more than the mixed cultures (sewage sludge inoculum) [40]. The selection of the inoculum in a particular growth phase (exponential phase) is also useful to attain high current in MFCs. It has been found that the bacteria in lag phase form thin biofilms and contain fewer amounts of c-type cytochromes while the bacteria in exponential phase form thicker biofilms and contain the higher number of c-type cytochromes, consequently generating higher electrical current [48]. Moreover, a selective inoculum of mixed culture referred as controlled inoculum (of known bacteria e.g. Pseudomonas aeruginosa, Azospira oryzae, Acetobacter peroxydans and Solimonas 
1 variicoloris) has shown to produce a higher power density than unknown inoculum [49]. A

2 study from our group revealed that such controlled inoculum can produce $100 \%$ more power

3 than anaerobic sludge (inoculum) in a double chamber MFC [49]. Further, some pre-

4 treatment methods of inoculum can also be employed to enhance the power output in the

5 MFCs [5].

6

7

8

The microbial community structure in an MFC is affected by the type of substrates used in the anode chamber, which could be simple substrates that are easily fermentable or complex substrates that are non-fermentable [3]. For example, acetate is commonly used in MFCs, and the exoelectrogens such as Geobacter and Shewanella spp. readily use acetate for electricity production [5]. Therefore, the abundant availability of acetate in the anode can exclude the effect of other fermentable bacteria. But wastewaters may contain simple as well as complex organic contents. Hence, pre-acclimation strategies can be employed to hydrolyse and ferment the wastewaters. For example, three pre-acclimation strategies were employed to evaluate the response of microbial community for electricity generation in an air-cathode MFC inoculated with anaerobic sludge from domestic wastewater [50]. In the first strategy, the MFC was pre-acclimated with glucose and acetate; in the second, with glucose before adding domestic wastewater and in the third strategy, the wastewater was directly used without any pre-acclimation [50]. The results revealed a great variation in the microbial community due to the pre-acclimation strategies. The MFC with first strategy was abundant with bacteria belonging to phylum Chloroflexi and genus Gemmobacter while the MFC preacclimated with second strategy contained predominantly Enterobacter and Escherichia. On the other hand, the MFC with third strategy was dominant with Dechloromonas and Anaerolinaceae. Moreover, the MFC with first strategy generated maximum current density and achieved maximum COD removal as compared to the other MFCs [50]. 
The researchers engaged in the MFC studies around the globe have endeavoured many innovative efforts to increase the power output of the fuel cells. Many of them are developing new MFC designs using different effective materials for the electrodes and membrane, operating MFCs at specific conditions (e.g., setting electrode potentials, maintaining $\mathrm{pH}$ of the electrolytes, pre-treatment of membranes and electrodes), treatment of the inoculum, and nanomodification of the electrodes. Some methods used to increase the electricity generation in the MFCs are discussed in the following section.

Electrode modification with metal catalyst or nanoparticles or chemical treatment has become a new trend to improve the performance of MFCs. The main purpose to modify the electrodes in MFCs is to increase the power outputs, in the anode by providing high surface area for the biofilm formation and to increase the exocellular electron transfer (EET) mechanisms. The cathode modifications are the centre of attraction to replace the highly costly platinum catalyst by cheaper catalysts of nearly or same catalytic properties [12]. Most of the studies regarding electrode modifications also claimed to decrease the internal resistance of the system as well as start-up time of the reactor. In the anode, different approaches have been employed to modify the electrodes to increase the power outputs either by simple modification methods such as heat-treated electrodes and nitrogen-doped electrodes or by some sophisticated tools such as by coating some highly effective catalysts (e.g., gold nanoparticles, graphene, carbon nanotubes (CNT) etc.) on the electrodes [51-55]. Interestingly, almost every kind of metal nanoparticles or other carbon nanoparticles have been used in the MFCs. Therefore, the researchers are now using electrode with different composite materials (e.g., CNT-gold-titania nanocomposites) to improve the performance [53]. Another effective method includes the use of nitrogen doped carbon nanoparticles to modify the electrode to enhance the EET mechanism. For example, nitrogen doped carbon 
nanoparticles were coated on carbon cloth electrodes in a two-chamber MFC inoculated with Shewanella oneidensis MR-1. The study revealed that the treated electrodes absorbed more electron mediators (flavins) secreted by the organism that subsequently increased the electron transfer rate. Consequently, the power density also increased more than three times as compared to untreated electrodes [55]. The anode can also be modified with metal or nonmetal nanoparticles (with different morphologies as well) to influence the EET and thus the performance of the MFCs. In a study, CNT powder was directly added to the anode chamber to increase the biofilm growth of G. sulfurreducens in a two-chamber MFC using plain carbon paper as the electrode material in both the chambers [52]. The addition of CNT powder in the anode chamber reduced the internal resistance of the system as well as the start-up time of the MFC. The shortened start-up time could be attributed to the promotion of the bacterial adhesion to the electrode material with the addition of CNT powder in the anode chamber [52]. The performance of the anode can be further improved by using different morphologies of the material that can provide more active sites and enhance biocompatibility with the electrode material. In a double chamber MFC, the anode (carbon cloth) was modified with bamboo-like carbon nanotubes that produced ca. four times higher power density than the MFC using plain carbon cloth as the anode [52].

It is evident that $\mathrm{Fe}$ (III) oxide exhibits high affinity for c-type cytochromes such as OmcA and MtrC present on the outer surface of Shewanella species [38, 39]. Therefore, it is more favourable for the bacteria to mediate the electrons from its outer surface to Fe (III) oxide. Moreover, it has been also revealed that Shewanella species are more attractive to iron oxide surfaces [5]. In other words, iron oxide surfaces enhance the microbial growth and increase the extracellular electron transfer, increasing the biofilm metabolic activity which can be advantageous for improving the performance of MFC-centred applications. For 
1 example, Song et al., utilized graphene/ $\mathrm{Fe}_{3} \mathrm{O}_{4}$ nanocomposites coated carbon paper as the

2 anode electrode to improve the bacterial activity in a two-chamber MFC inoculated with

3 Shewanella oneidensis MR-1 [56]. The results showed that the start-up time of the MFC was

4 significantly decreased with increase in $\mathrm{Fe}_{3} \mathrm{O}_{4}$ concentration, indicating a faster attachment of

5 bacteria onto the anode surface, which can be attributed to the high affinity of outer

6 membrane c-type cytochromes to iron oxide [56]. In addition, the MFC with modified anode

7 achieved a maximum current density of $1800 \mathrm{~mA} / \mathrm{cm}^{2}$, which was $\sim 6$ times higher than the

8 bare anode (carbon paper) [56]. In another study, $\mathrm{Fe}_{3} \mathrm{O}_{4}$-carbon cloth was used as an anode to

9 examine the beverage wastewater treatment and electricity generation [57]. The MFC

10 produced a maximum current density that was $100 \%$ higher than the bare cathode and a COD reduction of $\sim 52 \%$ was achieved [57]. The iron oxide layers can be prepared on the electrode surfaces to make them more biocompatible for enhanced microbial growth and functions. For example, stainless steel electrodes can be heat-treated to generate a layer of iron oxide on its surface. Evidently, Guo et al., prepared heat-treated stainless steel electrodes which generated a layer of iron oxide as confirmed by X-ray photoelectron spectroscopy [58]. This modification further improved the biofilm formation and enhanced the extracellular electron transfer as expected. Consequently, the current density was significantly increased. The MFC generated a maximum current density of $1.5 \mathrm{~mA} / \mathrm{cm}^{2}$, which was seven times higher than the bare electrode [58]. Previously, stainless steel mesh was modified with flame synthesis of carbon nanostructures on its surface, which increased its BET surface by 300 times as compared to the bare stainless steel mesh electrode. The microscopy results revealed that the addition of carbon nanostructures onto stainless steel mesh enhanced the biofilm formation. As a result, the MFC with modified anode produced a power density of $187 \mathrm{~mW} / \mathrm{m}^{2}$, which was 60 times higher than the bare anode [59]. 
The cathode modification is chiefly focused on to replace the platinum by some other cost-effective catalysts [12, 60-62]. Cobalt oxide and manganese oxide have shown the potential to substitute the platinum in MFCs. Specifically, cobalt oxide (with other materials e.g., iron phthalocyanine or nickel) has been repetitively experimented as a cathode catalyst for oxygen reduction reaction (ORR) [12]. Such MFCs with modified cathode electrode produced effective results but slightly lower than the MFCs with platinum (as cathode catalyst). An MFC using cobalt oxide-iron phthalocyanine as a cathode catalyst for oxygen reduction produced a maximum power density of ca. $655 \mathrm{~mW} / \mathrm{m}^{2}$, which was $37 \%$ higher than the MFC with iron phthalocyanine, indicating the effective potential of oxygen reduction activity of cobalt oxide for ORR [61]. In contrast, the MFC with a carnation-like manganese dioxide coated cathode produced 1.5 times higher power density than the plain electrode [62]. Alternatively, some bacteria (pure cultures or even mixed cultures) have also been used as cathode catalyst for oxygen reduction but could not produce satisfactory electric outputs [24]. Moreover, the overpotential obtained for ORR was also higher in the study due to the poor bacterial activity at the cathode, neglecting the choice of biocathode in real large scale MFC applications.

The electricity generated from MFCs can be further used to power electric instruments or machines. MFCs have been successfully applied to operate robots. Such robots are usually termed as "Gastrobots", which means robots with a stomach. These kinds of robots can metabolize the natural food or can be sustained by water or air. These robots digest the substrate fuel and convert it into electricity, which is usually stored in the batteries fitted in the robots, making them an autonomous power system. Evidently, MFCs were utilized to power a robot named as "Gastronome". Gastronome is thought to be the first robot that utilized biomass driven energy conversion technology [63]. Gastronome was built by 
1 joining train-like three wheeled wagons, as shown in Fig. 4. A stack of six MFCs was used in

2 the robot and $\mathrm{Ni}-\mathrm{Cd}$ batteries were utilized, which were charged by the electric output of the MFCs [63]. Ecobot-II is another example of a robot that was completely driven by MFCs for environmental monitoring [64]. A picture of Ecobot-II is shown in Fig. 5. The robot was connected to a wireless transmitter that was further connected to a sensor (which can be for temperature, toxicity, humidity etc.) [64]. In addition, the robot was packed with eight MFCs and utilized raw foodstuffs such as rotten fruits as substrate fuel. The authors also claimed that Ecobot-II was the first robot in the world powered by MFCs that was utilized for environmental monitoring [64]. In an alternative study, the MFCs were successfully used to power wireless sensors to detect the changes in temperature. The diagram of the sensor and telemetry system powered by the MFC is given in Fig. 6. In this study, the MFC was connected with a highly efficient electronic circuitry to provide a stable power for wireless sensor [65]. The electricity produced by the MFC was further stored in a capacitor and was used to power the telemetry system. However, the voltage generated by the system was lower $(2.1 \mathrm{~V})$ than needed for a commercial electronic circuit $(3.3 \mathrm{~V})$. Therefore, a DC-DC converter was utilized to increase the potential and to power the transmitter that received the data from the sensor and transmitted to the receiver [65]. Further, Tender et al. demonstrated the application of MFC for the first time in the world to power a meteorological buoy [66]. They used benthic type of MFCs and the meteorological buoy to measure air temperature, pressure, relative humidity, and water temperature. The results from this study are shown in Fig. 7.

\section{MFCS FOR WASTEWATER TREATMENT}

The process of wastewater treatment involves safe disposal or recycling of water which is highly polluted or contains toxic substances. Wastewater discharged from different industries 
1 can be particularly hazardous. According to an astounding report by Lux Research,

2 governments and water utilities across the world spent approximate \$28 billion in year 2012

3 to develop their existing wastewater treatment infrastructure that provided a surplus global

4 wastewater treatment capacity of 16.3 million cubic metres $\left(\mathrm{m}^{3}\right)$ per day. MFC technology

5 has the potential to provide an effective platform for the treatment of highly polluted

6 industrial wastewater or urban wastewater and can curb the financial expenditure, which can

7 be further used for other development programs of a country.

In the late nineteenth century, Habermann and Pommer (1991) used MFCs for continuous treatment of wastewaters for nearly 5 years [67]. They used sodium sulphate solution (different concentrations $(\%, 0.5-5)$ as the electrolyte in the anode, sulphate reducing microorganisms such as Proteus vulgaris, Escherichia coli, Pseudo-monas aeruoinosa and P. fluorescens, and two types of wastewaters (sewage works effluent and landfill effluent). The results showed that the MFC achieved a COD reduction of 35\% with sewage works effluent and $75 \%$ with landfill leachate [67]. In addition, a maximum anodic current density of 150 $\mathrm{mA} / \mathrm{cm}^{2}$ at a potential of $-50 \mathrm{mV}$ was also obtained in the demonstration [67].

In the later years, different types of wastewaters were used in MFCs for its treatment and bioenergy production [54-60, 68, 69, 70-75]. On one side of the picture, MFC technology can be used to treat the wastewater while on the other side, the wastewater can be used to provide substrate as the carbon source for the bacterial growth and hence for the end products of the oxidation process i.e. electrons and protons for sustainable bioelectricity generation [3]. Primary wastewater from an industry such as chocolate industry wastewater [29] or palm oil mill effluent (POME) [34] can be used to provide the inoculum or the biocatalysts for the substrate oxidation. Moreover, defined bacterial culture (pure or mixed) can be isolated from the wastewater that can be further used as inoculum for the MFCs [5]. The wastewater can be 
1 used as catholyte as well though it may contain some minerals that can act as electron

2 acceptors [29]. Though our review is focused on the performance of MFCs for wastewater treatment, the next section of the article reviews some studies that demonstrated the efficiency of MFCs for wastewater treatment and some approaches employed to improve the wastewater treatment efficiency of the MFCs.

The effect of different parameters on MFC performance has been studied. These primarily include chemical oxygen demand (COD), biochemical oxygen demand (BOD), total solids, total dissolved solids, acidity etc. Usually, standard methods are adopted to evaluate the wastewater treatment efficiency of the MFCs. Typically, COD test is performed (or is sufficient) to examine the performance of MFC toward wastewater treatment. Some examples of MFC studies demonstrated for wastewater treatment are given in Table 3. The MFCs have achieved up-to 98\% COD removal from wastewater [55, 56]. Almost all the studies demonstrated for wastewater treatment are coupled with the foremost application of MFCs i.e. electricity production.

Animal wastewaters contain high organic content and high concentrations of phosphate and nitrate in wastewater, the latter causing eutrophication of surface water. A few studies have demonstrated the use of animal wastewater in different MFCs for its treatment and bioenergy production. A study using swine wastewater in different MFCs (two chambered MFC and single chamber MFC) achieved maximum 92\% COD removal and approximately $83 \%$ ammonia reduction after operation of the MFC for around 100 hours [26]. Another study treated animal carcass wastewater (ACW) with high organic content in an up-flow tubular MFC [68]. The disposed animal carcasses can be further hydrolysed with alkaline treatment (sodium hydroxide or potassium hydroxide) into smaller constituents like amino acids, sugars and minerals forming a sterile solution referred as ACW (of BOD-70 g/l, 
1 COD-105 g/l and ammonia-1 g/l). The maximum COD reduction obtained in the

2 demonstration was more than $50 \%$ and the nitrate removal efficiency of MFC was nearly $380 \%[68]$.

4

Food wastewater or food industry wastewater is non-toxic but exhibits high BOD and is rich in sugars and starch as compared to other industrial wastewaters. A study using cereal wastewater in a double-chambered MFC achieved more than 95\% COD removal. The initial COD of the feed wastewater was $595 \mathrm{mg} / \mathrm{l}$ [69]. The production of starch foodstuffs (for example, potato chips) in food industries requires great usage of water, consequently releases large quantities of wastewater to the environment. Such starch processing wastewater (SPW) comprises high contents of proteins, carbohydrates, cellulose, vitamins and other nutrients. An MFC demonstration used SPW to evaluate the treatment efficiency of a double chambered MFC. The MFC achieved 98\% COD reduction after an operation of 140 days. This was accompanied by an ammonia-nitrogen removal efficiency of $91 \%$ [27]. In another study involving potato processing wastewater (PPW), 91\% of COD reduction was achieved [33]. Similarly, another organic-rich, nontoxic wastewater i.e. chocolate wastewater was used in a double chambered MFC by Patil et al. [29]. The results showed that maximum $75 \%$ COD was removed after the MFC operation in batch-mode. The BOD removal and total solid removal was ca. $65 \%$ and $68 \%$, respectively [29].

Conventional wastewater treatment techniques cannot effectively treat the wastewaters containing lignocellulosic biomass (e.g. cellulose, hemicellulose and lignin) However, Huang and Logan used paper recycling wastewater in a single chamber MFC (sMFC) for its treatment and electricity generation. The results suggested that the MFC, after nearly three weeks of operation, achieved more than $76 \%$ COD removal while ca. $96 \%$ of cellulose was removed by the bacteria [11]. This indicates that the microbial community in 
the MFC not only degraded the lignocellulose biomass and converted it to simpler sugars but

2 also extracted energy from such wastewaters to generate electricity.

3

4

The brewery wastewater has been widely investigated in different MFCs for its treatment and bioenergy production. The brewery wastewater exhibits high COD, up to 5000 $\mathrm{mg} / \mathrm{l}$. Moreover, it contains high levels of carbohydrates or sugars that can be used as electron donors in the MFCs. Here we present two examples of the studies that used brewery wastewater in MFCs. In the first example, air cathode sMFC was used with different concentrations of the wastewater and was operated in fed-batch mode [32]. When the wastewater with less COD value was used in the MFC, low COD removal was obtained and vice-versa. When COD concentration was $84 \mathrm{mg} / \mathrm{l}$ and $1600 \mathrm{mg} / \mathrm{l}$, the COD removal was $\sim 58 \%$ and $98 \%$, respectively [32]. In the second study, sMFC was operated in continuous mode with a hydraulic resistance time (HRT) of 2.13 hours. The wastewater was diluted with deionized water and the COD ranged between $600 \mathrm{mg} / \mathrm{l}$ and $660 \mathrm{mg} / \mathrm{l}$. The sMFC achieved $43 \%$ and $46 \%$ COD removal, respectively [31].

The effect of temperature on treatment efficiency of MFCs was investigated by Ahn and Logan using air-cathode sMFC [69]. They operated the fuel cell (batch mode and continuous mode) at two different temperatures i.e. ambient temperature $\left(23 \pm 3^{\circ} \mathrm{C}\right)$ and mesophilic temperature $\left(30 \pm 1^{\circ} \mathrm{C}\right)$. The results showed that the $\% \mathrm{COD}$ removal, as well as the COD removal rate was higher in the MFCs operated at mesophilic temperature than the ambient temperature. Moreover, ca. 10\% more nitrogen removal was achieved from the MFCs operated at higher temperature. Overall, the MFCs in the fed-batch mode removed more than 2.5 times COD as compared to MFCs operated in continuous mode [70]. 
Treatment of wastewaters from different other mills (agro-industries and oil

2 industries) have been also investigated in MFCs. Such wastewaters show high COD and are

toxic. For example, cassava mill effluent can have a COD over $16000 \mathrm{mg} / \mathrm{l}$ and a cyanide concentration of ca. $86 \mathrm{mg} / \mathrm{l}$ [71]. A $30 \mathrm{~L}$ double chambered MFC achieved nearly 90\% COD removal after 120 hours of operation [71]. Palm oil industries release large amount of highly toxic wastewater, referred to as palm oil mill effluent (POME). POME exhibits COD and BOD as high as 50000 and $25000 \mathrm{mg} / \mathrm{l}$, respectively [34]. Cheng et al. treated POME in an upflow membrane less MFC (UML-MFC) coupling MFC and up-flow anaerobic sludge blanket (UASB) reactors. This integrated system achieved 96\% COD and 94\% nitrogen removal [34].

Usually, the MFCs produce more power density with wastewater of high COD values. However, the highly concentrated substrate can cause fouling of the PEM, resulting in the restriction of protons, which consequently leads to the accumulation of protons in the anode chamber (low $\mathrm{pH}$ ) and less availability of protons in the cathode (high $\mathrm{pH}$ ). Therefore, concentrated wastewaters are sometimes diluted to maintain proper functioning of the MFCs. Furthermore, some pre-treatment methods can be employed to change the physiochemical or biological properties of the wastewater for enhanced performance of the MFCs. For example, the wastewater can be autoclaved to kill the methanogens (the anaerobic bacteria that yield methane as a metabolic by-product) that otherwise use the organic matter to produce methane instead of protons and electrons. A study showed that MFC with the autoclaved wastewater produced ca. 5\% more power density than with raw wastewater [26]. Another pre-treatment method i.e. sonication was shown to be useful to increase the performance of the MFCs considerably. This approach was employed using raw wastewater that produced ca. $16 \%$ more power density and increased the COD removal efficiency by nearly $5 \%$. The 
sonication process may improve the performance of the MFC by altering the biodegradability of the organic matter present in the wastewater or changing the molecular weight or particle size spectra of the organic matter. Moreover, wastewater stirring has also shown marginal improvement in the COD removal in the MFC [26]. However, some of these pre-treatment options are energy-intensive and may not be ideal for scale up.

Compared to industrial wastewaters, domestic wastewater is more biodegradable. Domestic wastewater can be a promising substrate for bioenergy production by MFCs. This approach can be utilized to make eco-friendly public toilets, which can generate electricity and can help to keep the surrounding environment neat and clean. For example, a single chamber air-cathode MFC (3-stage MFC/struvite extraction process system) was utilized to treat human urine with simultaneous extraction of struvite $\left(\mathrm{NH}_{4} \mathrm{MgPO}_{4} \cdot 6 \mathrm{H}_{2} \mathrm{O}\right)$, which is an eco-friendly fertilizer. Struvite crystals are generally present in human urine; thus, these can be extracted from urine using MFCs [77]. The anode was inoculated with anaerobic sludge. Human urine, supplemented with $0.5 \%$ yeast extract and $1 \%$ tryptone, was used as the substrate. The MFC achieved a power of $14.32 \mathrm{~W} / \mathrm{m}^{3}$ after first stage, which reduced to 11.76 $\mathrm{W} / \mathrm{m}^{3}$ after the third stage [77]. Also, the MFC enhanced urea hydrolysis during the operation, which was advantageous for struvite precipitation process. In their successive study, they added sea salts in the human urine (substrate) that increased the electricity generation as well as the struvite extraction [78]. After the addition of sea salts the power output increased by $10 \%$, while the struvite extraction enhanced from 21 to $94 \%$. Besides, the COD removal also improved from $16 \%$ to $18 \%$ [78]. In addition, the research group of Ioannis Ieropoulos at University of the West of England, Bristol (UK) had a successful fieldtrial on the MFC-based public toilets in Glastonbury Music Festival. A special urinal was fabricated and the collective urine was fed in the stack of MFCs connected in parallel, as 
1 shown in Fig. 8 [79]. The MFCs were directly connected to LED lights to monitor the

2 electricity generation. The trial was run for approximately 3 months and $2.5-5 \mathrm{~L}$ of urine was converted daily to power. For a period of 5 weeks, an average power of $75 \mathrm{~mW}$ was achieved each day and a maximum of $98 \%$ COD reduction was observed during the trial [79]. In addition to human urine, human feces have been also used in MFCs to generate electricity. For example, a two chamber MFC was fed with human feces wastewater for electricity generation and its treatment. The wastewater was firstly fermented prior to use in MFCs to enhance the power generation. The results showed that the MFC achieved a maximum power density of $70.8 \mathrm{~mW} / \mathrm{m}^{2}$ and the total COD reduction was $78 \%$ after an operation of $190 \mathrm{~h}$ [79].

In MFCs, the wastewater treatment efficiency can be further improved by operating the fuel cells for longer periods. For example, an MFC (air-cathode) was operated for four cycles; each cycle lasted for approximately 35 days. The results suggested that the COD removal after the first cycle was ca. $95 \%$ which increased to more than $98 \%$ after the end of four cycles (after 140 days of MFC operation) [27]. This can be attributed to the longer duration available for the microorganisms to degrade the complex substrates completely into simpler substances. However, the coulombic efficiency achieved in the demonstration was ca. $7 \%$, indicating that most of the substrates did not convert to electricity, which could be due to the following reasons: (i) oxygen diffusion, (ii) production of fermented products, (iii) oxidization of other electron acceptors, and (iv) biomass production [27]. The integration of MFCs with other wastewater treatment technologies can extract more energy, thereby further improving the pollutant removal efficiency. Generally, the bacteria in MFCs effectively degrade the simpler or low-strength wastewaters whereas bioreactors such as anaerobic digester (AD) or UASB treat high-strength wastewaters [2]. Therefore, the wastewaters with 
1 complex composition (e.g. POME) can be subjected to the fermentation in UASB that can

2 provide more suitable or simpler substrates for electricity generation in MFCs. Moreover, the

3 residual organics present in the effluent of UASB can be further removed in the MFCs.

4

Generally, the MFCs with smaller volumes $(10-100 \mathrm{ml})$ are used in the laboratory with synthetic wastewaters. However, a significant number of efforts have been made to scale-up the MFC technology. For example, Zhu et al., constructed a 2-L MFC with staggered and inline electrode system using graphite rods [80], demonstrating faster start-up and higher power output as compared to the MFC with inline electrode array. Evidently, the former MFC produced a maximum power density of $23.8 \mathrm{~W} / \mathrm{m}^{3}$ and the latter MFC generated a maximum power density of $19.1 \mathrm{~W} / \mathrm{m}^{3}$ [80]. This higher power density can be accredited to the improved mass transfer in staggered electrode array. Besides, the MFC also achieved a 84\% COD reduction [80]. In another study, the MFC was further scaled-up to 20-L to treat brewery wastewater [81]. No catalyst and ion exchange membrane was used in this study. This MFC was operated for one year and a stable 75\% COD removal performance was observed during the first five months [81]. Moreover, a maximum of $\sim 94 \%$ of COD reduction was achieved at a flow rate of $1 \mathrm{ml} / \mathrm{min}$ (hydraulic retention time=313) when the MFC was connected to an external resistor of $10 \Omega$ [81]. In a subsequent demonstration, a MFC with 90-L capacity (stacked with five modules) was fabricated by Dong et al. [82]. This was operated in an energy self-sufficient mode for approximately 180 days to treat brewery wastewater (diluted and real wastewater) [82]. A schematic diagram of the 90-L MFC is shown in Fig. 9. The results suggested that the MFC obtained a maximum COD reduction of $\sim 87 \%$ and $85 \%$ with diluted and real wastewater, respectively. Besides, the MFC with real wastewater obtained higher energy production $\left(0.097 \mathrm{kWh} / \mathrm{m}^{3}\right)$ as compared with diluted wastewater $\left(0.056 \mathrm{kWh} / \mathrm{m}^{3}\right)[82]$. Therefore, it can be concluded that the scale-up of MFC 
1 technology has shown substantial improvements for wastewater treatment as well as for

2 bioenergy production, which may pave the way for commercialization of MFCs in the near 3 future.

\section{5. MFCs FOR BIOREMEDIATION OF SPECIFIC CONTAMINANTS}

5 The exoelectrogens produce electrons from their metabolism in the anode chamber of an 6 MFC, which need to be reduced at the cathode chamber. Therefore, an electron acceptor is 7 provided at the cathode to overcome the potential losses. In addition, a catalyst can also be 8 used to increase the reduction reaction rate. Usually, the electron acceptors that exhibit a high 9 redox potential, faster kinetics, a low cost and easy availability are significant and of great interest in MFC applications. For example, oxygen is one of the promising and widely used electron acceptors in the MFCs. In MFC system, various organic and inorganic toxic elements or compounds can be utilized as the electron acceptor in the cathode chamber for its removal or reduction to less toxic form and simultaneously for the electric current generation. For examples, metal ions, perchlorate, nitrobenzene, azo dyes, nitrate $\left(\mathrm{NO}_{3}{ }^{-}\right)$etc. have been used as electron acceptors in different MFCs to explore the bioremediation potential of this technology. Some examples of MFC performance for bioremediation application are given in Table 4.

The high concentration of toxic heavy metals (e.g. cadmium, mercury, lead, arsenic, chromium etc.) in industrial effluents is harmful to the cellular metabolism of the flora and the fauna living on our planet. Therefore, the wastewaters that contain high concentration of toxic heavy metals need to be reduced into nontoxic form before they are discharged into the environment. MFCs have shown a great potential for the reduction of heavy metals both when used in the anode as well as the electron acceptor in the cathode chamber [72-75]. 
electron acceptor, to achieve higher power output from the cell. Before discussing the MFC potential for the removal of heavy metals let us get an idea about the processes that are responsible for heavy metal removal/reduction in MFCs.

Various heavy metals have been investigated in the anode chamber as well as in the cathode chamber of MFCs for their eco-friendly removal. For anodic removal, generally, a specific concentration of a heavy metal or toxic element is added in the anolyte (supplemented with carbon source and bacterial inoculum). On the other hand, a heavy metal with a high redox potential can be used as the electron acceptor in the cathode chamber. A few mechanisms have been demonstrated that are responsible for the removal of heavy metals or other toxic elements during MFC operation. The first mechanism is biosorption that has been widely recognized for the removal of toxic elements in the MFCs [73]. Biosorption is a combined term for the processes such as microprecipitation, complexation, chelation, coordination, and ion exchange. The biomolecules like polysaccharides, proteins and lipids contain the functional groups such as amine, sulfate, carboxylate, hydroxyl, and phosphate that help in the biosorption process to remove the heavy metals or toxic pollutants. These biomolecules may be present in the anolyte or on the bacterial cell walls, which play a major role in the removal of toxic pollutants. Moreover, some processes like biological oxidation, chemical oxidation, volatilization, anode electrode adsorption have been found responsible for the sulfide removal during the MFC operation.

A single chamber air-cathode MFC demonstrated for the removal of cadmium $(\mathrm{Cd})$ and zinc $(\mathrm{Zn})$ showed high removal efficiencies i.e. 90\% and 97\%, respectively [72]. Moreover, in a dual chamber MFC, vanadium containing wastewater was employed as the cathodic electron acceptor for its simultaneous removal. The fuel cell after 10 days' operation achieved ca. $70 \%$ removal of $\mathrm{V}(\mathrm{V})$ with a maximum power density of ca. $970 \mathrm{~mW} / \mathrm{m}^{2}$ [73]. 
1 In another study, a two-chamber MFC obtained a maximum power of ca. $431 \mathrm{~mW} / \mathrm{m}^{2}$ with

2 more than $99.5 \%$ removal of $\mathrm{Hg}^{2+}$, which was used as an electron acceptor in the fuel cell

3 [74]. Also ammonia-copper (II) complexes have been substantially recovered from 4 wastewater using MFC technology. $\mathrm{Cu}\left(\mathrm{NH}_{3}\right)_{4}{ }^{2+}$ complexes can be reduced to $\mathrm{Cu}$ or $\mathrm{Cu}_{2} \mathrm{O}$. In 5 a study, 96\% copper was successfully removed after 12 hours of operation of an MFC at a 6 pH-of $9.0[75]$.

Different types of dyes are used for the colouring purpose in the textile industry that

8 results in the generation of a colossal volume of dye wastewater per year around the world.

9 Dye wastewater contains many toxic and recalcitrant organic molecules and carcinogenic chemicals [6]. The discharge of such wastewater is threatening to the environment, animals as well as to the plants. Therefore, treatment of such hazardous wastewater is essential before its discharge to the environment. MFC technology provides an eco-friendly alternative for the treatment of dye wastewater and simultaneous bioelectricity generation. MFCs use microorganisms, therefore, the dyes can be reduced by different decolorization mechanisms involving enzymes, low molecular weight redox mediators, and chemical reduction by biogenic reductants. In the MFCs, the dye decolorization occurs in the anode chamber biologically under anaerobic conditions. For example, the azo bond of congo red dye was broken into the intermediates such as aromatic amines that can be completely degraded abiotically in cathode chamber [76].

An sMFC with bioanode and biocathode was demonstrated to decolorize an azo dye congo red, after the operation of the fuel cell for approximately one day. More than $98 \%$ congo red decolourization was achieved in that study [76]. Transfer of electrons from anode microorganisms and protons through PEM leads to the degradation of azo bond $(-\mathrm{N}=\mathrm{N}-)$ in the cathode. Reduction of azo bond results in the formation of colourless and biodegradable 
1 aromatic amines [76]. Dechlorinating microorganisms can be used in MFCs for the

2 bioremediation of pentachloroethene (PCE) and trichloroethene (TCE) to reduce them into non-toxic end product ethene. Strycharz et al. successfully used Geobacter lovleyi and graphite electrodes (as the electron donor) for reductive dechlorination of PCE [83]. A consortium of anaerobic and aerobic bacteria in the cathodic chamber of dual chamber MFC demonstrated efficient degradation of pentachlorophenol (PCP). In the study, degradation rate for PCP was investigated at different $\mathrm{pH}$ values and variant temperatures. The most effective degradation rates achieved at a constant temperature of $50^{\circ} \mathrm{C}$ and $\mathrm{pH} 6$ were $0.52 \mathrm{mg} / \mathrm{L}-\mathrm{h}$ and $0.36 \mathrm{mg} / \mathrm{L}-\mathrm{h}$, respectively [83]. In addition, Geobacter species have shown the tendency to reduce aqueous, soluble $U$ (VI) into an insoluble form as $U$ (IV). Multiple lines of evidence suggest that $G$. sulfurreducens entails the outer-surface $c$-type cytochromes for U (VI) reduction but do not require pili for the same purpose [84]. Further investigation revealed that G. sulfurreducens strain lacking the pilA gene reduced U (VI) to the parallel extent to wild type strain. Similarly, $c$-type cytochromes are also indispensable for S. oneidensis to reduce U (VI). Gene deletion studies demonstrated the importance of outer membrane, decaheme cytochrome MtrC in the electron transport to $\mathrm{U}$ (VI), as the strains deficient in $\mathrm{mtrC}$ and/or omcA were unable to reduce U (VI) [85]. Moreover, MFCs utilizing anaerobic biocathodes have shown the ability to reduce highly toxic $\mathrm{Cr}$ (VI) to much less toxic $\mathrm{Cr}$ (III) and subsequent precipitation to $\mathrm{Cr}(\mathrm{OH})_{3}$ with simultaneous electricity generation [86]. The MFC with set biocathode potentials reduced $\mathrm{Cr}$ (VI) with increased reduction rate of $19.7 \mathrm{mg} / \mathrm{L}-\mathrm{d}$. Further, use of Shewanella oneidensis MR-1 (produced riboflavin, an electron shuttle mediator to transfer electrons) as a biocatalyst in the cathode under aerated conditions in the presence of lactate showed increased reduction rate for Cr (VI) [87]. An MFC fed with sulfide and glucose and predominated by Firmicutes obtained sulfide removal efficiencies of up-to $85 \%$ and a power output of $572.4 \mathrm{~mW} / \mathrm{m}^{2}$ at acurrent density of $1094.0 \mathrm{~mA} / \mathrm{m}^{2}$ [88]. 
1 Recently, analysis of 16S rRNA revealed that a strain showing similarity to Klebsiella sp. is

2 capable of bioremediation of cyanide-containing wastewater in MFC. That study achieved more than $99.5 \%$ removal of cyanide and ca. $88 \%$ COD removal rate [89]. The investigations described in this section reflect that the MFC technology is a promising alternative for the bioremediation of hazardous contaminants.

\section{MFCs AS BIOSENSORS}

The online water-monitoring system is indispensable to maintain the proper usage of wastewaters from industries or municipal to conserve the aquatic environment as well as the public health. The MFC has been proven a successful biosensor to detect the organic compounds and contaminants in the wastewaters [90-92]. The conventional biosensors usually require a transducer whereas MFC in itself acts as a transducer, therefore MFC can prove to be a cost-effective biosensor. In the MFC-based biosensor, the exoelectrogens in the anode chamber serve as a signal generator or biological recognition element whereas electrodes and PEM (if used) acts as the transducer. The main advantage of the MFCbiosensor is its long-term stability. This is because the exoelectrogenic biofilms extend the lifespan of sensing element and curtail the replacement of sensing elements.

The basic principle of MFC-based biosensor is presented in Fig. 10. Generally, a toxin (or a sample to be detected) is provided at the anode chamber and its effect on the voltage output is measured. A sudden change in the voltage i.e. either fall or rise in the voltage is taken as the signal for toxin detection. For example, if a toxic element (i.e. chromium) is injected in the anode chamber, a sudden or slow fall in the voltage can be expected because it inhibits growth and activity of the exoelectrogens and, consequently, decreases the voltage [93]. On the other hand, if a carbon source (i.e. acetate) is injected in the anode chamber, a rise in the voltage is anticipated because it accelerates the growth and activity of the 
exoelectrogens and, therefore, increases the voltage [93]. The results from this study are

2 depicted in Fig. 11, which demonstrates different MFCs as the biosensors using low and high concentrations of different types of contaminants. Typically, the demonstration used three samples i.e. chromium (acute toxin), iron (non-toxic metal) and acetate (organic substrate) at different concentrations (chromium- $1 \mathrm{mg} / \mathrm{L}$ and $8 \mathrm{mg} / \mathrm{L}$, iron- $1 \mathrm{mg} / \mathrm{L}$ and $48 \mathrm{mg} / \mathrm{L}$, acetate$200 \mathrm{mg} / \mathrm{L}$ ) in separate MFCs. The injection of acute toxic and non-toxic metal suddenly decreased the voltage marginally at low concentrations and severely at high concentrations. On the other hand, the addition of carbon substrate increased the voltage [93].

The MFC sensors can be operated in two modes. The first is flow-through and the second is flow-by electrodes. In the first mode, the water sample moves through the porous electrode, while in the second mode, the water sample flows parallel to the electrode surface [94]. The operation of MFC sensor in a flow-through mode can improve the diffusion of ions and the electrolytes, thereby increasing the sensitivity of the MFC-based toxicity sensors. Moreover, a study reported that flow-through anode in an MFC sensor also enhanced the diffusion of protons through anodic biofilm, improving the biocatalysis of the substrates by the exoelectrogens [95]. Evidently, the sensitivity of an MFC-based toxicity sensor was increased approximately 40 times by using a flow-through anode as compared to the flow-by anode [96].

According to the Michaelis-Menten equation, the biocatalytic activity of exoelectrogens in the anode chamber depends on the concentration of dissolved organic matter and it keeps increasing until the concentration of the organic matter reaches a saturation point [97]. MFC sensors are usually operated in turn-off mode for toxicity monitoring, and the metabolic activity of exoelectrogens can be supressed by adding a certain concentration of a toxic pollutant in the anolyte, resulting a certain change in the electric output $[94,96]$. The biological toxicity of the target toxic pollutants is generally measured by 
1 correlating the concentration of the toxin to the electric signal output. Therefore, current

2 change $(\Delta I)$ and inhibition ratio (IR) can be evaluated. Further, $\Delta I$ can be utilized to obtain

3 the sensitivity of the MFC-based toxic sensor by normalizing the $\Delta I$ to the concentration of

4 the toxic agent. On the other hand, IR represents the amplitude of the electric signal output

5 and can be used to evaluate the toxicity of pollutants [98]. However, it is still unclear what

6 maximum concentration of the toxic agent is required to obtain a signal output for toxicity-

7 monitoring.

In the conventional MFC-based sensors, the sensitivity of toxic agents depends on the

9 bioanode in the system or we can say bioanode acts as a sensing element in the MFC sensor to monitor the water toxicity. But recently, Yong et al. designed an MFC sensor with biocathode as the sensing element. The results revealed that the MFC sensor with biocathode showed better sensitivity than the MFC sensor with bioanode [99]. Such MFC sensors could be advantageous in comparison to bioanode because they do not need organic matter supplementation for baseline signal output and can reduce the negative effects of combined shock of toxicity and organic matter. Moreover, the signal output of an MFC sensor is greatly dependent and influenced by the performance of the anode and the cathode. Therefore, the modifications can be done in both the chambers to reduce the response time and increase the detection capacity. For example, the anode potential of the MFC sensor significantly affects the biosensor sensitivity and, therefore, can be optimized using a potentiostat. The anode potential usually determines the energy level of the electrons that get transferred from the surface of exoelectrogens to the anode surface and, hence, affects the electron transfer rate and the electric output signal [94]. A study revealed that the MFC sensor operated at a constant anode potential $(-1.5 \mathrm{~V})$ showed the highest sensitivity and an unbiased measurement of toxicity as compared to the MFC sensor without applying anode potential 
1 [96]. Similarly, the cathode of MFC sensor can be altered to improve its water-monitoring.

2 The performance of cathode (stability and catalysis) can affect the amplitude and the

$5 \mathrm{Cu}^{2+}$ and acidic toxicity. An immediate voltage drop was observed when the MFC was

6 injected with $\mathrm{Cu}^{2+}(2-6 \mathrm{mg} / \mathrm{L})$ and the $\mathrm{pH}$ was decreased from 6 to 4 [100]. Results are given 7 in Fig. 12.

8

The application of an MFC-based BOD sensor with municipal or industrial wastewater could be more challenging in real-world applications because the wastewaters contain easily degradable organic matters as well as toxic pollutants. During the operation of an MFC-based BOD sensor, sudden changes in BOD and toxicity could simultaneously occur [101]. In a MFC-based sensor, the current density decreases with respect to the toxicity of the toxic agents, while the current density increases with rise in BOD [101]. Therefore, the sudden variation in BOD might wane the responses of MFC sensor for toxicity. Evidently, a study demonstrated that a combined shock of BOD and toxicity affected the signal output when using the MFC sensor for the detection of Cr (IV) [102]. In other words, it can be stated that signal interference is caused by the combined shock of BOD and toxicity when MFC sensor is used for water-monitoring. Recently, Yong et al. studied the effect of organic matter concentration (in anode) on toxicity monitoring to avoid the signal interference by the combined shock of BOD and toxicity [103]. The study revealed that the background organic matter concentration should be fixed at a high level of oversaturation for maximizing the signal output when the ' $\Delta I$ ' is selected relative to the concentration of a toxic agent. On the other hand, IR should be fixed to a lower value near to the detection limit to maximize the signal output [103]. The results of this study are shown in Fig. 13. 
The passage of oxygen into the anode chamber affects the metabolic activity of anaerobic microorganisms in MFC-based biosensors, thereby, affecting the biosensor sensitivity. Therefore, it is important to solve this limitation to improve the performance of these kinds of biosensors. The oxygen diffusion can be diminished by placing an ion exchange membrane between the cathode and the anode that is less permeable to oxygen. Generally, nafion is used as the proton exchange membrane in MFCs, but it shows high oxygen permeability [94]. Recently, a sulfonated ketone ether membrane was applied in a MFC-based biosensor replacing nafion. The MFC with the new membrane showed better sensitivity results as compared to nafion [104]. The better performance was attributed to the lower oxygen permeability of the membrane [104]. The other challenges include its long response time and detection reliability to replace the commercialized real water-monitoring systems. However, the longer response time for detection of contaminants can be minimized by modifying the MFC sensor structure. For example, in a study, the response time was significantly reduced from $36 \mathrm{~min}$ to $5 \mathrm{~min}$ by decreasing the volume of anode from $25 \mathrm{ml}$ to $5 \mathrm{ml}$ in the MFC [104]. On the other hand, the detection reliability can be further ameliorated by connecting various MFCs in parallel. Such MFC array has been reported for effective water quality monitoring [94].

A few MFC-based biosensors have been commercialized. One such product is named Biomonitoring system (HATOX-2000), which has been invented by a Korean company and can be utilized for online monitoring of water toxicity. More detailed information of this product can be accessed from elsewhere (www.ecotrade.org). 
1

2

3

4

5

6

7

8

9

\section{MICROBIAL ELECTROLYSIS CELLS FOR HYDROGEN PRODUCTION}

An MFC produces electricity from organic waste while a microbial electrolysis cell (MEC) produces hydrogen gas. The working principle of an MEC is similar to an MFC as the electrons generated by the exoelectrogens in the anode combines with protons at the cathode to produce hydrogen gas as the final product. But unlike MFC, electricity is provided in the MEC to produce hydrogen. Theoretically a voltage of 0.2 to $0.8 \mathrm{~V}$ is required to reduce the protons to form hydrogen. Such low voltage is easily achievable in the MFC. Therefore, an MFC can be used to supply the voltage to the MEC for hydrogen production. The electrode material used in the MFCs can be employed in the MECs as well. Moreover, the exoelectrogens are also required to produce hydrogen gas in MECs. In MECs, similar to MFCs, a cathode catalyst such as platinum is used to overcome the overpotentials to drive hydrogen production. Unlike MFCs, the MECs require strictly anaerobic conditions for hydrogen production. However, the higher concentration of hydrogen gas promotes the growth of methane-producing microorganisms. Subsequently, the hydrogen gas is contaminated by methane and the resultant hydrogen output is decreased. Different types of organic sources and wastewater can be applied in MEC for hydrogen production. Notably, MEC has shown higher hydrogen yields than that obtained with fermentation. For example, the maximum theoretical yield of $7 \mathrm{~mol}-\mathrm{H}_{2} / \mathrm{mol}$-glycerol by oxidation is achievable. The hydrogen yields reported in some studies using fermentation vary from 0.05-1.05 mol$\mathrm{H}_{2} /$ mol-glycerol [106, 107], but a hydrogen yield of $3.9 \mathrm{~mol}^{-\mathrm{H}_{2}} / \mathrm{mol}$-glycerol has been achieved using MEC [108]. In addition, a hydrogen yield of $7.2 \mathrm{~mol}-\mathrm{H}_{2} / \mathrm{mol}$-glucose was also obtained in the study against the maximum theoretical yield of $12 \mathrm{~mol}-\mathrm{H}_{2} / \mathrm{mol}$ - glucose [108]. 
There are some obstacles that limit the application of MECs at the large scale. For example, a single MFC generally produces an OCV of approximately $0.8 \mathrm{~V}$ and a resultant working voltage of $\sim 0.5 \mathrm{~V}$ can be achieved in an MFC [109]. This decrease in voltage could be due to higher internal resistance in the MFC system, energy utilization by bacteria, and electrode overpotentials [109]. Therefore, three or five MFCs can be connected in series to increase the resultant voltage output. But the voltage reversal can reduce the voltage output over the long-term [109]. This problem was resolved by Hatzell et al. by using a capacitor in the circuit to prevent the voltage reversal. In this study, the MFCs were connected in a parallel configuration to charge the capacitors. Then the capacitors were connected in series to discharge the voltage to the MECs. Such a system increased the hydrogen production rate approximately 2.3 times as compared to coupled systems without capacitors [110]. Another major limitation in MECs is the consumption of hydrogen by methanogens to produce methane, which consequently reduces the hydrogen generation. Many approaches have been used to inhibit the methanogens in MECs. For example, the cathode can be exposed to oxygen or ultraviolet radiation to inhibit the methanogens. In a demonstration, the exposure of cathode to air decreased the methane concentration from $3.4 \%$ to less than $1 \%$ [111]. On the other hand, the exposure of ultraviolet (UV) radiation in the MEC maintained high concentrations of hydrogen $(91 \%)$, while without UV irradiation, methane concentrations increased significantly [112]. Recently, the use of antibiotics has shown the potential to inhibit the methanogens [113]. In a study, Catal et al. used different concentrations of four antibiotics (neomycin sulfate, 2-bromoethane sulfonate, 2-chloroethane sulfonate, and 8-azahypoxanthine) to measure the inhibition of methanogenesis on a mixed culture community to improve the hydrogen production. The results showed that the increasing concentrations of the antibiotics decreased the concentration of methane effectively that resulted in a comparatively higher hydrogen production [114]. The third major problem that hinders the 
1 use of MEC at pilot scale is the necessity of a catalyst at the cathode. Usually, platinum is

2 used as the cathode catalyst in MECs that is very expensive. Moreover, it can be easily poisoned by sulfide present in the water. Therefore, its replacement with a catalyst which is cost-effective and has similar catalytic properties is required to launch the technology at a large scale. Some catalysts have been already experimented in MECs to replace platinum. For example, Yang et al. recently used polyaniline/multi-walled carbon nanotube as the cathode catalyst in a single chamber MEC. The results suggested that a maximum hydrogen production rate of $1.04 \mathrm{~m}^{3} / \mathrm{m}^{3} /$ day was achieved with the catalyst, which was comparable to the performance with platinum [114]. The same catalyst was further used in a different study with biocathodes that achieved a maximum hydrogen production rate of $0.67 \mathrm{~m}^{3} / \mathrm{m}^{3} /$ day [115]. Moreover, nano- $\mathrm{Mg}(\mathrm{OH})_{2} /$ graphene composites at different concentrations were demonstrated as the cathodic catalyst in MEC to improve hydrogen production. The cathodic hydrogen recovery and hydrogen production rate obtained with the catalyst were ca. $84 \%$ and $0.63 \mathrm{~m}^{3} / \mathrm{m}^{3} /$ day, which were higher as compared to the $\mathrm{Pt} / \mathrm{C}$ cathode [116].

\section{CONCLUSIONS AND CHALLENGES}

The MFCs provide a suitable, eco-friendly alternative to produce energy and to treat wastewater simultaneously. Several wastewaters ranging from low-strength to high-strength have been utilized in MFCs for their treatment and electricity generation simultaneously. However, the power outputs achieved in the MFCs are low and can be enhanced by the following approaches; 1) a suitable design that results in low internal resistance; 2) using nanoparticles that increase the electron transfer mechanisms; 3) use of genetically engineered microorganisms; 4) addition of pre-treated inoculum or control inoculum; 5) decreasing the start-up time of the MFC. For example, graphene/ $\mathrm{Fe}_{3} \mathrm{O}_{4}$ nanocomposites coated carbon paper as the anode electrode decreased the start-up time and achieved a maximum current density 
1 of $1800 \mathrm{~mA} / \mathrm{cm}^{2}$, which was $\sim 6$ times higher than the bare anode [56]. The electricity

2 generated from MFCs can be further used to power electric instruments or machines. As noted earlier, MFCs have been successfully applied to operate the "Gastrobots" for bioenergy production and environmental monitoring.

Further efficient treatment of wastewater can be achieved by operating the fuel cells at mesophilic temperatures. Moreover, the MFCs integrated with other anaerobic fermentation technologies such as with UASB, have shown enhanced COD removal efficiency. Significant efforts have been made to scale-up the MFC technology. For example, a MFC with 90-L capacity obtained a maximum COD reduction of $\sim 87 \%$ with brewery wastewater [82].

MFCs have shown a great potential for the reduction of heavy metals or toxic pollutants when used in the anode as well as in the cathode chamber as the electron acceptor. The heavy metals with a high redox potential are of great interest to act as the electron acceptor, to achieve higher power output from the cell. The biomolecules that may be present in the anolyte or on the bacterial cell walls contain the functional groups, which play a major role in the removal of toxic pollutants. MFCs have achieved heavy metal removal of even upto $99.5 \%\left(\mathrm{Hg}^{2+}\right)$ and $97 \%(\mathrm{Zn})$. The MFCs can also be applied as a BOD or COD sensor to detect the availability of a toxic pollutant in the wastewater. The voltage drop/rise is taken as the signal for the detection of the toxin or the sample. The change in voltage is usually proportional to the concentration of the toxin. The low sensitivity and detection reliability are the main challenges in MFC-based biosensors. The sensitivity of an MFC-based toxicity sensor can be improved by operating them in a flow-through mode. A study showed that the sensitivity of the biosensor increased approximately 40 times by using a flow-through anode as compared to the flow-by anode [96]. In addition, an MFC can be amended to an MEC to 
1 produce another biofuel i.e., hydrogen energy, while the MFC may be a substantial

2 alternative to supply the required voltage. One of the major limitations in MECs is the

4 the hydrogen generation. However, the use of antibiotics and exposure of ultraviolet

5 radiations have shown the potential to inhibit the methanogens [113]. The results showed that

6 the increasing concentrations of the antibiotics decreased the concentration of methane

7 effectively, resulting a higher hydrogen production [114].

8

The MFC technology has been used for various applications, however, there are some challenges that need to be addressed to make the technology economically viable. The first prime hurdle is a feasible design for upscaling the MFC. The previous designs exhibit some drawbacks such as high internal resistance, electrode spacing, exchange of anolyte and catholyte across the PEM etc. when we think to scale up them for long-term operations. However, some designs have already been introduced but have not been explored at the industrial scale. The second challenge is to provide cost-effective electrode materials and PEM (if used) for MFCs. For scale up, the available electrode materials such as carbon paper and carbon cloth would be very expensive. Another obstacle is the choice of an electron acceptor at the cathode. Oxygen is abundantly available and is the preeminent choice for the electron acceptor. But continuous sparging of oxygen at the cathode can also affect the activity of anaerobic microbial community at the anode during long-term operations since oxygen can diffuse through the PEM to the anode. Platinum is most commonly used for oxygen reduction reaction, but it is very expensive, and a cheaper alternative is required. For example, at the small scale (MFC of $250 \mathrm{ml}$ capacity), commercially available $0.5 \mathrm{mg} / \mathrm{cm}^{2}$ $20 \%$ platinum on carbon paper of $20 \mathrm{~cm}^{2}$ costs $~ 250$ US\$ (Fuel Cell Earth, USA). If we want to scale up the MFC reactor, we need larger electrode and obviously, a large amount of 
1 platinum. This makes the use of platinum uneconomical at the large scale. Moreover,

2 platinum turns poisonous when it reacts with certain elements/chemicals in the water such as

3 sulphide, making the use of platinum impractical for wastewater treatment application.

4 Therefore, the replacement of platinum is the must in scaling-up the MFCs.

\section{ACKNOWLEDGMENTS}

6 This research was financially supported by Universiti Malaysia Pahang under Internal

7 Research Scheme Grant (RDU 140379).

\section{REFERENCES}

9

[1] Logan BE, Wallack MJ, Kim KY, He W, Feng Y, Saikaly P. Assessment of microbial fuel cell configurations and power densities. Environmental Science \& Technology Letters 2015: 2 (8): 206-214.

[2] Papaharalabos G, Greenman J, Melhuish C, Ieropoulos I. A novel small scale microbial fuel cell design for increased electricity generation and waste water treatment. Int J Hydrogen Energy 2015; 40: 4263-8.

[3] Pant D, Van Bogaert G, Diels L, Vanbroekhoven K. A review of the substrates used in microbial fuel cells (MFCs) for sustainable energy production. Bioresource technology 2010;101(6):1533-43.

[4] Xu B, Ge Z, He Z. Sediment microbial fuel cells for wastewater treatment: challenges and opportunities. Environ Sci: Water Res Technol 2015; 1: 279-84

[5] Kumar R, Singh L, Wahid ZA. Exoelectrogens: Recent advances in molecular drivers involved in extracellular electron transfer and strategies used to improve it for microbial fuel cell applications. Renew Sust Energ Rev 2016; 56: 1322-36. 
1 [6] Hai FI, Yamamoto K, Fukushi K. Hybrid treatment systems for dye wastewater. Critical Reviews in Environmental Science and Technology 2007;37(4):315-77.

[7] Fornero JJ, Rosenbaum M, Angenent LT. Electric Power Generation from Municipal, Food, and Animal Wastewaters Using Microbial Fuel Cells. Electroanal 2010; 22: $832-43$.

[8] Qian Y, Xu Y, Yang Q, Chen Y, Zhu S, Shen S. Power generation using polyaniline/multi-walled carbon nanotubes as an alternative cathode catalyst in microbial fuel cells. Int J Energy Res 2014; 38: 1416-23.

[9] Yong XY, Feng J, Chen YL, Shi DY, Xu YS, Zhou J, Wang SY, Xu L, Yong YC, Sun YM, Shi CL, OuYang PK, Zheng T. Enhancement of bioelectricity generation by cofactor manipulation in microbial fuel cell. Biosens Bioelectron 2014; 56: 19-25.

[10] Yoshizawa T, Miyahara M, Kouzuma A, Watanabe K. Conversion of activatedsludge reactors to microbial fuel cells for wastewater treatment coupled to electricity generation. J Biosci Bioeng 2014; 118: 533-9.

[11] Huang L, Logan BE. Electricity generation and treatment of paper recycling wastewater using a microbial fuel cell. Appl Microbiol and Biotechnol 2008; 80: 34955.

[12] Kumar R, Singh L, Zularisam AW, Hai FI. Potential of porous Co 3 O 4 nanorods as cathode catalyst for oxygen reduction reaction in microbial fuel cells. Bioresource Technology 2016;220:537-42. 
[13] Lifang D, FrangBai L, Shungui Z, Yin HD, Jinren NI. A study of electron-shuttle mechanism in Klebsiella pneumoniae based microbial fuel cells. Environ SciTechnol 2010; 55: 99-104.

[14] Kang CS, Eaktasang N, Kwon DY, Kim HS. Enhanced current production by Desulfovibrio desulfuricans biofilm in a mediator-less microbial fuel cell. Bioresour Technol 2014; 165: 27-30.

[15] Qiao Y, Li CM, Bao SJ, Lu Z, Hong Y. Direct electrochemistry and electrocatalytic mechanism of evolved Escherichia coli cells in microbial fuel cells. Chem Commun 2008; 11: 1290-92.

[16] Raghavulu SV, Goud RK, Sarma PN, Mohan SV. Saccharomyces cerevisiae as anodic biocatalyst for power generation in biofuel cell: influence of redox condition and substrate load. Bioresour Technol 2011; 102: 2751-2757.

[17] Wetser K, Sudirjo E, Buisman CJN, David PBTBS. Electricity generation by a plant microbial fuel cell with an integrated oxygen reducing biocathode. Appl Energy 2015; 137: 151-57.

[18] Nandy A, Kumar V, Kundu PP. Utilization of proteinaceous materials for power generation in a mediatorless microbial fuel cell by a new electrogenic bacteria Lysinibacillus sphaericus VA5. Enzyme Microb Technol 2013; 53: 339-44.

[19] Wu Y, Zhang X, Li S, Lv X, Cheng Y, Wang X. Microbial biofuel cell operating effectively through carbon nanotube blended with gold-titania nanocomposites modified electrode. Electrochimica Acta 2013; 109: 328-32. 
[20] Li Y, Williams I, Xu Z, Li B, Li B. Energy-positive nitrogen removal using the integrated short-cut nitrification and autotrophic denitrification microbial fuel cells (MFCs). Appl Energy 2016; 163: 352-60.

[21] Li W, Zhang S, Chen G, Hua Y. Simultaneous electricity generation and pollutant removal in microbial fuel cell with denitrifying biocathode over nitrite. Applied Energy 126 (2014) 136-41.

[22] Yang Y, Ding Y, Hu Y, Cao B, Rice SA, Kjelleberg S, Song H. Enhancing bidirectional electron transfer of Shewanella oneidensis by a synthetic flavin pathway. ACS Synth Biol 2015: 7: 815-23.

[23] Katuri KP, Enright AM, O'Flaherty V, Leech D. Microbial analysis of anodic biofilm in a microbial fuel cell using slaughterhouse wastewater. Bioelectrochem 2012;87: 164-71.

[24] Guo F, Fu G, Zhang Z. Performance of mixed-species biocathode microbial fuel cells using saline mustard tuber wastewater as self-buffered catholyte. Bioresour Technol 2015; 180: 137-43.

[25] Hassan SH, Kim YS, Oh SE. Power generation from cellulose using mixed and pure cultures of cellulose-degrading bacteria in a microbial fuel cell. Enzyme Microb Technol 2012; 51: 269-73.

[26] Min B, Kim J, Oh S, Regan JM, Logan BE. Electricity generation from swine wastewater using microbial fuel cells. Water Res 2005; 39: 4961-68.

[27] Lu N, Zhou S, Zhuang L, Zhang J, Ni J. Electricity generation from starch processing wastewater using microbial fuel cell technology. Biochem Eng J 2009; 43: 246-51. 
[28] Rodrigo MA, Cañizares P, Lobato J, Paz R, Sáez C, Linares JJ. Production of electricity from the treatment of urban waste water using a microbial fuel cell, $\mathbf{J}$ Power Sources 2007; 169: 198-204.

[29] Patil SA, Surakasi AP, Koul S, Ijmulwar S, Vivek A, Shouche YS, Kapadnis BP. Electricity generation using chocolate industry wastewater and its treatment in activated sludge based microbial fuel cell and analysis of developed microbial community in the anode chamber. Bioresour Technol 2009; 100: 5132-39.

[30] Y Feng, Yang Q, Wang X, Liu Y, Lee H, Ren N. Treatment of biodiesel production wastes with simultaneous electricity generation using a single-chamber microbial fuel cell, Bioresour Technol 2011; 102: 411-15.

[31] Wen Q, Wu Y, Cao D, Zhao L, Sun Q. Electricity generation and modeling of microbial fuel cell from continuous beer brewery wastewater. Bioresour Technol 2009: 100: 4171-75.

[32] Feng Y, Wang X, Logan BE, Lee H. Brewery wastewater treatment using air-cathode microbial fuel cells. Appl Microbiol and Biotechnol 2008; 78; 873-80.

[33] Durruty I, Bonanni PS, Gonzalez JF, Busalmen JP. Evaluation of potato-processing wastewater treatment in a microbial fuel cell. Bioresour Technol 2012; 105: 81-87.

[34] Cheng J, Zhu X, Ni J, Borthwick A. Palm oil mill effluent treatment using a two-stage microbial fuel cells system integrated with immobilized biological aerated filters. Bioresour Technol 2010; 101: 2729-34. 
[35] Fang F, Zang GL, Sun M , Han-Qing Y. Optimizing multi-variables of microbial fuel cell for electricity generation with an integrated modeling and experimental approach. Appl Energy 2013; 110: 98-103.

[36] Prathap P, Cesar IT, Tyson B, Sudeep CP, Bradley GL, Bruce ER. Kinetic, Electrochemical, and Microscopic Characterization of the Thermophilic, AnodeRespiring Bacterium Therminocola ferriacetica. Environ Sci Technol 2013; 47: 493440.

[37] F Kracke, I Vassilev, JO Krömer. Microbial electron transport and energy conservation-the foundation for optimizing bioelectrochemical systems. Front Microbiol 2015; 6: 575.

[38] Pirbadian S, Barchinger SE, Leung KM, Byun HS, Jangir Y, Bouhenni RA, Reed SB, Romine MF, Saffarini DA, Shi L, Gorby YA. Shewanella oneidensis MR-1 nanowires are outer membrane and periplasmic extensions of the extracellular electron transport components. Proceedings of the National Academy of Sciences 2014;111(35):128838.

[39] Okamoto A, Kalathil S, Deng X, Hashimoto K, Nakamura R, Nealson KH. Cellsecreted flavins bound to membrane cytochromes dictate electron transfer reactions to surfaces with diverse charge and pH. Scientific reports 2014;4:5628.

[40] Nevin KP, Richter H, Covalla SF., Johnson JP, Woodard TL, Orloff AL, Jia H, Zhang M. Lovley DR. Power output and columbic efficiencies from biofilms of Geobacter sulfurreducens comparable to mixed community microbial fuel cells. Environ Microbiol 2008; 10: 2505-14. 
[41] Gorby YA, Yanina S, McLean JS, Rosso KM, Moyles D, Dohnalkova A, Beveridge TJ, Chang IS, Kim BH, Kim KS, Culley DE, Reed SB, Romine MF, Saffarini DA, Hill EA, Shi L, Elias DA, Kennedy DW, Pinchuk G, Watanabe K, Ishii S, Logan B, Nealson KH, Fredrickson JK. Electrically conductive bacterial nanowires produced by Shewanella oneidensis strain MR-1 and other exoelectrogens. Proc. Natl. Acad. Sci. USA 2006; 103: 11358-63.

[42] Richter H, McCarthy K, Nevin KP, Johnson JP, Rotello VM, Lovley DR. Electricity generation by Geobacter sulfurreducens attached to gold electrodes. Langmuir 2008; 24: 4376-79.

[43] Clarke TA, Edwards MJ, Gates AJ, Hall A, White GF, Bradleya J, Reardonb CL, Shib L, Beliaevb AS, Marshallb MJ, Wangb Z, Watmougha NJ, Fredricksonb JK, Zacharab JM, Butta JN, Richardson DJ. Structure of a cell surface decaheme electron conduit. Proc Natl Acad Sci USA 2011; 108: 9384-89.

[44] Coursolle D, Baron DB, Bond DR, Gralnick JA. The Mtr respiratory pathway is essential for reducing flavins and electrodes in Shewanella oneidensis. J Bacteriology 2010; 192: 467-74.

[45] Inoue K, Leang C, Franks AE, Woodard TL, Nevin KP, Lovley DR. Specific localization of the c-type cytochrome OmcZ at the anode surface in current-producing biofilms of Geobacter sulfurreducens. Environ Microbiol Rep 2010; 3: 211-17.

[46] Malvankar NS, Lovley DR. Microbial nanowires: a new paradigm for biological electron transfer and bioelectronics. ChemSusChem 2012; 5: 1039-46. 
[47] Okamoto A, Kalathil S, Deng X, Hashimoto K, Nakamura R, Nealson KH. Cellsecreted flavins bound to membrane cytochromes dictate electron transfer reactions to surfaces with diverse charge and pH. Sci Rep 2014; 4: 5628.

[48] Lebedev N, Strycharz-Glaven SM, Tender LM. High Resolution AFM and SingleCell Resonance Raman Spectroscopy of Geobacter sulfurreducens Biofilms Early in Growth. Front Energy Res 2014; 2: 1-8.

[49] Baranitharan E, Khan MR, Yousuf A, Teo WFA, Tan GYA, Cheng CK. Enhanced power generation using controlled inoculum from palm oil mill effluent fed microbial fuel cell. Fuel 2015; 143: 72-79.

[50] Park Y, Cho H, Yu J, Min B, Kim HS, Kim BG, Lee T. Response of microbial community structure to pre-acclimation strategies in microbial fuel cells for domestic wastewater treatment. Bioresource Technology 2017;233:176-83.

[51] Ci S, Wen Z, Chen J, He Z. Decorating anode with bamboo-like nitrogen-doped carbon nanotubes for microbial fuel cells. Electrochem Commun 2012; 14: 71-74.

[52] Liang P, Wang H, Xia X, Huang X, Mo Y, Cao X, Fan M. Carbon nanotube powders as electrode modifier to enhance the activity of anodic biofilm in microbial fuel cells. Biosens Bioelectron 2011; 26: 3000-04.

[53] Wu Y, Zhang X, Li S, Lv X, Cheng Y, Wang X. Microbial biofuel cell operating effectively through carbon nanotube blended with gold-titania nanocomposites modified electrode. Electrochim Acta 2013; 109: 328-32. 
[54] Kumar R, Singh L, Wahid ZA, Din MF. Exoelectrogens in microbial fuel cells toward bioelectricity generation: a review. International Journal of Energy Research 2015;39(8):1048-67.

[55] Yu YY, Guo CX, Yong YC, Li CM, Song H. Nitrogen doped carbon nanoparticles enhanced extracellular electron transfer for high-performance microbial fuel cells anode, Chemosphere 2015; 140: 26-33.

[56] Song RB, Zhao CE, Gai PP, Guo D, Jiang LP, Zhang Q, Zhang JR, Zhu JJ. Graphene/Fe3O4 Nanocomposites as Efficient Anodes to Boost the Lifetime and Current Output of Microbial Fuel Cells. Chemistry-An Asian Journal. 2016.

[57] Leu HJ, Lin CY, Chang FC, Tsai MJ. Fe3O4-modified carbon cloth electrode for microbial fuel cells from organic wastewaters. Desalination and Water Treatment 2016;57(60):29371-6.

[58] Guo K, Soeriyadi AH, Feng H, Prévoteau A, Patil SA, Gooding JJ, Rabaey K. Heattreated stainless steel felt as scalable anode material for bioelectrochemical systems. Bioresource technology 30;195:46-50.

[59] Lamp JL, Guest JS, Naha S, Radavich KA, Love NG, Ellis MW, Puri IK. Flame synthesis of carbon nanostructures on stainless steel anodes for use in microbial fuel cells. Journal of Power Sources 2011;196(14):5829-34.

[60] Zhang P, Li K, Liu X. Carnation-like MnO2 modified activated carbon air cathode improve power generation in microbial fuel cells. Journal of Power Sources 2014; 264: $248-53$. 
[61] Ahmed J, Yuan Y, Zhou L, Kim S. Carbon supported cobalt oxide nanoparticles-iron phthalocyanine as alternative cathode catalyst for oxygen reduction in microbial fuel cells. Journal of Power Sources 2012; 208: 170-75.

[62] Li X, Hu B, Suib S, Lei Y, Li B. Manganese dioxide as a new cathode catalyst in microbial fuel cells. Journal of Power Sources 2010; 195: 2586-91.

[63] Wilkinson, S. "Gastronome" - A Pioneering Food Powered Mobile Robot. Proceedings of the 2000 IASTED Int. Conference on Robotics and Applications, 2000: 318-037,

[64] Ieropoulos I, Melhuish C, Greenman J, Horsfield I, Hart J. Energy autonomy in robots through Microbial Fuel Cells. CiteSeerX-Scientific Literature Digital Library and Search Engine, The Pennsylvania State University, USA. 2004.

[65] Shantaram A, Beyenal H, Veluchamy RR, Lewandowski Z. Wireless sensors powered by microbial fuel cells. Environmental science \& technology 2005;39(13):5037-42.

[66] Tender LM, Gray SA, Groveman E, Lowy DA, Kauffman P, Melhado J, Tyce RC, Flynn D, Petrecca R, Dobarro J. The first demonstration of a microbial fuel cell as a viable power supply: powering a meteorological buoy. Journal of Power Sources 2008;179(2):571-5.

[67] Habermann W, Pommer EH. Biological fuel cells with sulphide storage capacity. Applied microbiology and biotechnology, 1991;35(1):128-33.

[68] Li X, Zhu N, Wang Y, Li P, Wu P, Wu J. Animal carcass wastewater treatment and bioelectricity generation in up-flow tubular microbial fuel cells: Effects of HRT and non-precious metallic catalyst. Bioresour Technol 2013; 128: 454-60. 
[69] Oh SE, Logan BE. Hydrogen and electricity production from a food processing wastewater using fermentation and microbial fuel cell technologies. Water Res 2005; 39 : 4673-82.

[70] Ahn Y, Logan BE. Effectiveness of domestic wastewater treatment using microbial fuel cells at ambient and mesophilic temperatures. Bioresour Technol 2010; 101: 46975.

[71] Kaewkannetra P, Chiwes W, Chiu TY. Treatment of cassava mill wastewater and production of electricity through microbial fuel cell technology. Fuel 2011; 90: 274650.

[72] Abourached C, Catal T, Liu H. Efficacy of single-chamber microbial fuel cells for removal of cadmium and zinc with simultaneous electricity production. Water Res 2014; 51: 228-33.

[73] Zhang B, Feng C, Ni J, Zhang J, Huang W. Simultaneous reduction of vanadium (V) and chromium (VI) with enhanced energy recovery based on microbial fuel cell technology. J Power Sources 2012; 204: 34-39.

[74] Zhang LJ, Tao HC, Wei XY, Lei T, Li JB, Wang AJ, Wu WM. Bioelectrochemical recovery of ammoniaecopper(II) complexes from wastewater using a dual chamber microbial fuel cell. Chemosphere 2012; 89: 1177-82.

[75] Wang Z, Lim B, Choi C. Removal of $\mathrm{Hg}^{2+}$ as an electron acceptor coupled with power generation using a microbial fuel cell. Bioresour Technol 2011; 102: 6304-07. 
[76] Kong F, Wang A, Cheng H, \& Liang B. Accelerated decolorization of azo dye Congo red in a combined bioanode-biocathode bioelectrochemical system with modified electrodes deployment. Bioresour Technol 2014; 151: 332-39.

[77] You J, Greenman J, Melhuish C, Ieropoulos I. Electricity generation and struvite recovery from human urine using microbial fuel cells. Journal of Chemical Technology and Biotechnology 1;91(3):647-54.

[78] Merino-Jimenez I, Celorrio V, Fermin DJ, Greenman J, Ieropoulos I. Enhanced MFC power production and struvite recovery by the addition of sea salts to urine. Water Research 2017;109:46-53.

[79] Ieropoulos IA, Stinchcombe A, Gajda I, Forbes S, Merino-Jimenez I, Pasternak G, Sanchez-Herranz D, Greenman J. Pee power urinal-microbial fuel cell technology field trials in the context of sanitation. Environmental Science: Water Research \& Technology 2016;2(2):336-43.

[80] Zhu X, Zhang L, Li J, Liao Q, Ye DD. Performance of liter-scale microbial fuel cells with electrode arrays: effect of array pattern. international journal of hydrogen energy 2013;38(35):15716-22.

[81] Lu M, Chen S, Babanova S, Phadke S, Salvacion M, Mirhosseini A, Chan S, Carpenter K, Cortese R, Bretschger O. Long-term performance of a 20-L continuous flow microbial fuel cell for treatment of brewery wastewater. Journal of Power Sources 2017;1-14.

[82] Dong Y, Qu Y, He W, Du Y, Liu J, Han X, Feng Y. A 90-liter stackable baffled microbial fuel cell for brewery wastewater treatment based on energy self- sufficient mode. Bioresource technology 2015;195:66-72. 
[83] Strycharz SM, Woodard TL, Johnson JP, Nevin KP, Sanford R, Löffler FE, Lovley DR. Graphite electrode as a sole electron donor for reductive dechlorination of tetrachlorethene by Geobacter lovleyi. Appl Environ Microbiol 2008; 74: 5943-47.

[84] Orellana R, Leavitt JJ, Comolli LR, Csencsits R, Janot N, Flanagan KA, Gray AS, Leang C, Izallalen M, Mester T. U(VI) reduction by a diversity of outer surface c-type cytochromes of Geobacter sulfurreducens. Appl Environ Microbiol 2013; 79: 636974.

[85] Marshall MJ, Beliaev AS, Dohnalkova AC, Kennedy DW, Shi L, Wang ZM, Boyanov MI, Lai B, Kemner KM, McLean JS, Reed SB, Culley DE, Bailey VL, Simonson CJ, Saffarini DA, Romine MF, Zachara JM, Fredrickson JK. c-Type cytochrome-dependent formation of U(IV) nanoparticles by Shewanella oneidensis. Plos Biology 2006; 4: e268.

[86] Huang L, Chai X, Chen G, Logan BE. Effect of set potential on hexavalent chromium reduction and electricity generation from biocathode microbial fuel cells. Environ Sci Technol 2011; 45: 5025-31.

[87] Xafenias N, Zhang Y, Banks CJ. Enhanced performance of hexavalent chromium reducing cathodes in the presence of Shewanella oneidensis MR-1 and lactate. Environ Sci Technol 2013; 47: 4512-20.

[88] Zhang B, Zhang J, Liu Y, Hao C, Tian C, Feng C, Zhang Z. Identification of removal principles and involved bacteria in microbial fuel cells for sulfide removal and electricity generation. Int J Hydrogen Energy 2013; 38: 14348-55. 
[89] Wang W, Feng Y, Tang X, Li H, Du Z, Yang Z, Du Y. Isolation and Characterization of an Electrochemically Active and Cyanide-degrading Bacterium Isolated from a Microbial Fuel Cell. RSC Adv 2014; 4: 36458-63.

[90] Chang IS, Jang JK, Gil GC, Kim M, Kim HJ, Cho BW, Kim BH. Continuous determination of biochemical oxygen demand using microbial fuel cell type biosensor. Biosens Bioelectron 2004; 19: 607-13.

[91] Liu Z, Liu J, Zhang S, Xing XH, Su Z. Microbial fuel cell based biosensor for in situ monitoring of anaerobic digestion process. Bioresour Technol 2011; 102: 10221-29.

[92] Kumar R, Singh L, Zularisam AW. Microbial Fuel Cells: Types and Applications. InWaste Biomass Management-A Holistic Approach 2017 (pp. 367-384). Springer International Publishing.

[93] Liu B, Lei Y, Li B. A batch-mode cube microbial fuel cell based "shock" biosensor for wastewater quality monitoring. Biosens Bioelectron 2014; 62: 308-14.

[94] Sun JZ, Peter Kingori G, Si RW, Zhai DD, Liao ZH, Sun DZ, et al. Microbial fuel cell-based biosensors for environmental monitoring: a review. Water Sci Technol $2015 ; 71: 801-9$

[95] Torres CI, Kato Marcus A, Rittmann BE. Proton transport inside the biofilm limits electrical current generation by anode-respiring bacteria. Biotechnology and Bioengineering 2008;100(5):872-81.

[96] Jiang Y, Liang P, Zhang C, Bian Y, Yang X, Huang X, Girguis PR. Enhancing the response of microbial fuel cell based toxicity sensors to $\mathrm{Cu}$ (II) with the applying of 
flow-through electrodes and controlled anode potentials. Bioresource technology $2015 ; 190: 367-72$.

[97] Kim BH, Chang IS, Cheol Gil G, Park HS, Kim HJ. Novel BOD (biological oxygen demand) sensor using mediator-less microbial fuel cell. Biotechnology letters 2003;25(7):541-5.

[98] Kim M, Hyun MS, Gadd GM, Kim HJ. A novel biomonitoring system using microbial fuel cells. Journal of environmental monitoring 2007;9(12):1323-8.

[99] Jiang Y, Liang P, Liu P, Wang D, Miao B, Huang X. A novel microbial fuel cell sensor with biocathode sensing element. Biosensors and Bioelectronics 2017;94:34450.

[100] Jiang Y, Liang P, Liu P, Yan X, Bian Y, Huang X. A cathode-shared microbial fuel cell sensor array for water alert system. International Journal of Hydrogen Energy 2016;42(7):4342-8.

[101] Abourached C, Catal T, Liu H. Efficacy of single-chamber microbial fuel cells for removal of cadmium and zinc with simultaneous electricity production. Water research 2014;51:228-33.

[102] Liu B, Lei Y, Li B. A batch-mode cube microbial fuel cell based "shock" biosensor for wastewater quality monitoring. Biosensors and Bioelectronics 2014;62:308-14.

[103] Jiang Y, Liang P, Liu P, Bian Y, Miao B, Sun X, Zhang H, Huang X. Enhancing Signal Output and Avoiding BOD/Toxicity Combined Shock Interference by Operating a Microbial Fuel Cell Sensor with an Optimized Background 
Concentration of Organic Matter. International Journal of Molecular Sciences 2016;17(9):1392.

[104] Ayyaru S, Dharmalingam S. Enhanced response of microbial fuel cell using sulfonated poly ether ether ketone membrane as a biochemical oxygen demand sensor. Analytica chimica acta 2014;818:15-22.

[105] Moon H, Chang IS, Kang KH, Jang JK, Kim BH. Improving the dynamic response of a mediator-less microbial fuel cell as a biochemical oxygen demand (BOD) sensor. Biotechnol Lett 2004; 26:1717-21.

[106] Temudo MF, Poldermans R, Kleerebezem R, van Loosdrecht MCM. Glycerol fermentation by (open) mixed cultures: a chemostat study. Biotechnol Bioeng 2008; 100: 1088-98.

[107] Ito T, Nakashimada Y, Senba K, Matsui T, Nishio N. Hydrogen and ethanol production from glycerol-containing wastes discharged after biodiesel manufacturing process. J Biosci Bioeng 2005; 100: 260-5.

[108] Selembo PA, Perez JM, Lloyd WA, Logan BE. High hydrogen production from glycerol or glucose by electrohydrogenesis using microbial electrolysis cells. Int $\mathbf{J}$ Hydrogen Energy 2009; 4: 5373-81.

[109] Oh SE, Logan BE. Voltage reversal during microbial fuel cell stack operation. J. Power Sources 2007; 167: 11- 17.

[110] Hatzell MC, Kim Y, Logan BE. Powering microbial electrolysis cells by capacitor circuits charged using microbial fuel cell. J Power Sources 2013; 229: 198-202. 
1 [111] Tice RC, Kim Y. Methanogenesis control by electrolytic oxygen production in microbial electrolysis cells. Int J Hydrogen Energy 2014; 39: 3079-86.

[112] Hou Y, Luo H, Liu G, Zhang R, Li J, Fu S. Improved hydrogen production in the microbial electrolysis cell by inhibiting methanogenesis using ultraviolet irradiation. Environ Sci Technol 2014; 48: 10482-88.

[113] Catal T, Lesnik KL, Liu H. Suppression of methanogenesis for hydrogen production in single-chamber microbial electrolysis cells using various antibiotics. Bioresour Technol 2015; 187: 77-83.

[114] Yang Q, Jiang Y, Xu Y, Qiu Y, Chen Y, Zhu S, Shen S. Hydrogen production with polyaniline/multi-walled carbon nanotube cathode catalysts in microbial electrolysis cells. J Chem Technol Biotechnol 2015; 90: 1263-69.

[115] Chen Y, Xu Y, Chen L, Li P, Zhu S, Shen S. Microbial electrolysis cells with polyaniline/multi-walled carbon nanotube-modified biocathodes. Energy 2015; 88: 377-84.

[116] Dai H, Yang H, Liu X, Jian X, Liang Z. Electrochemical evaluation of nano$\mathrm{Mg}(\mathrm{OH})_{2} /$ graphene as a catalyst for hydrogen evolution in microbial electrolysis cell. Fuel 2016; 174: 251-56. 
55

2

3

4

5

6

7

8

9

10

11 


\section{Highlights}

The state-of-the-art information on major applications of MFCs and strategies to improve them is provided in this article.

$>$ The basic principles of all the applications are thoroughly discussed.

The obstacles that limit the technology to use in real world applications are reported.

$>$ Many approaches such as electrode modification, genetic engineering etc. can be utilized to improve the MFC performances. 


\section{List of tables}

Table 1. Performance of microbial fuel cells for bioelectricity generation using pure cultures

Table 2. Performance of microbial fuel cells for bioelectricity generation using mixed cultures

Table 3. Performance of microbial fuel cells for wastewater treatment

Table 4. Performance of microbial fuel cells for bioremediation 


\begin{tabular}{|c|c|c|c|c|c|}
\hline Inoculum & Type of MFC & Substrate & Electrode materials & Current density/Power density & References \\
\hline Klebsiella pneumonia & Single-chamber MFC & Glucose & Carbon cloth & $199 \mathrm{~mA} / \mathrm{m}^{2}$ & 25 \\
\hline Desulfovibrio desulfuricans & Double-chamber MFC & Wastewater & Graphite felt & $233 \mathrm{~mA} / \mathrm{m}^{2}$ & 26 \\
\hline Escherichia coli & Double-chamber MFC & Glucose & $\begin{array}{l}{ }^{1} \mathrm{PAN} / \mathrm{TiO}_{2} \text { composite-anode } \\
\text { Carbon cloth-cathode }\end{array}$ & $3390 \mathrm{~mA} / \mathrm{m}^{2}$ & 27 \\
\hline $\begin{array}{l}\text { Saccharomyces } \\
\text { cerevisiae }\end{array}$ & Single-chamber MFC & Synthetic wastewater & Graphite plates & $282 \mathrm{~mA} / \mathrm{m}^{2}$ & 28 \\
\hline Thermincola ferriatica & Double-chamber MFC & Acetate & Graphite carbon fibres & $12000 \mathrm{~mA} / \mathrm{m}^{2}$ & 14 \\
\hline $\begin{array}{l}\text { Lysinbacillus } \\
\text { sphaericus }\end{array}$ & Double-chamber MFC & Glucose & Graphite felt & $85 \mathrm{~mW} / \mathrm{m}^{2}$ & 30 \\
\hline Citrobacter sp. & Single-chamber MFC & Acetate & Carbon cloth & $205 \mathrm{~mA} / \mathrm{m}^{2}$ & 31 \\
\hline Ochrobactrum sp. & Double-chamber MFC & Xylose & Carbon fibres brush & $2625 \mathrm{~mW} / \mathrm{m}^{3}$ & 32 \\
\hline Shewanella putrefaciens & Single-chamber MFC & Lactate & Carbon cloth & $4920 \mathrm{~mW} / \mathrm{m}^{3}$ & 33 \\
\hline Scenedesmum & Double-chamber MFC & Acetate & $\begin{array}{l}\text { Carbon fiber brush-anode } \\
\text { Carbon cloth-cathode }\end{array}$ & $1926 \mathrm{~mW} / \mathrm{m}^{2}$ & 34 \\
\hline Shewanella oneidensis & Mini-MFC & Lactate & Graphite-felt & $3000 \mathrm{~mW} / \mathrm{m}^{2}$ & 35 \\
\hline
\end{tabular}


Carbon cloth-cathode

Chlorella vulgaris

Double-chamber MFC Wastewater

Carbon felt-anode

$2485 \mathrm{~mW} / \mathrm{m}^{3}$

Carbon cloth-cathode

Rhodopseudomonas

Single-chamber MFC

Wastewater

Carbon paper-anode

$2720 \mathrm{~mW} / \mathrm{m}^{2}$

palustris

Carbon cloth-cathode

Coriolus versicolor

Double-chamber MFC

${ }^{2}$ ABTS

Carbon fibres

$320 \mathrm{~mW} / \mathrm{m}^{3}$

Geobacter metallireducens

Double-chamber MFC

Domestic wastewater

Carbon paper

$40 \mathrm{~mW} / \mathrm{m}^{2}$

Geobacter sulfurreducens

Double-chamber MFC

Acetate

Note-: ${ }^{1} \mathrm{PAN}=$ Polyaniline

${ }^{2}$ ABTS $=2$, 2'-Azino-bis (3-ethylbenzthiazoline-6-sulfonic acid)

Units of surface power density are given in milliwatts per square meter; volume power density in watts per cubic meter; and current density in milliampere per square meter. 
Table 2. Performance of microbial fuel cells for bioelectricity generation using mixed cultures

\begin{tabular}{|c|c|c|c|c|c|}
\hline Source of inoculum & Type of MFC & Substrate & Electrode material & $\begin{array}{l}\text { Current density/Power density } \\
\qquad / \text { Voltage }\end{array}$ & Reference \\
\hline Dairy manure wastewater & Single-chamber MFC & Dairy manure wastewater & Graphite fiber brush & $190 \mathrm{~mW} / \mathrm{m}^{2}$ & 42 \\
\hline Potato wastewater & Single-chamber MFC & Potato wastewater & Graphite fiber brush & $217 \mathrm{~mW} / \mathrm{m}^{2}$ & 42 \\
\hline Activated sludge & Double-chamber MFC & Acetate, glucose & Carbon paper & $410 \mathrm{mV}$ & 43 \\
\hline Primary wastewater & Double-chamber MFC & Acetate & Graphite rods & $152 \mathrm{~mA} / \mathrm{m}^{2}$ & 44 \\
\hline Activated sludge & Single-chamber MFC & Acetate, glucose & Carbon cloth & $1084 \mathrm{~mW} / \mathrm{m}^{2}$ & 45 \\
\hline Activated sludge & Double-chamber MFC & ${ }^{1} \mathrm{POME}$ & Polyacrylonitrile carbon felt & $107 \mathrm{~mW} / \mathrm{m}^{2}$ & 46 \\
\hline Activated sludge & Single-chamber MFC & Glucose & Carbon cloth & $68 \mathrm{~mW} / \mathrm{m}^{2}$ & 47 \\
\hline Activated sludge & Single-chamber MFC & Acetate & $\begin{array}{l}\text { Graphite coated with graphene } \\
\text {-anode, carbon cloth-cathode }\end{array}$ & $670 \mathrm{~mW} / \mathrm{m}^{2}$ & 48 \\
\hline Primary wastewater & Single-chamber MFC & Acetic acid & $\begin{array}{l}\text { Graphite fiber brushes-anode } \\
\text { Carbon cloth-cathode }\end{array}$ & $835 \mathrm{~mW} / \mathrm{m}^{2}$ & 49 \\
\hline Primary wastewater & Single-chamber MFC & Ethanol & $\begin{array}{l}\text { Graphite fiber brushes-anode } \\
\text { Carbon cloth-cathode }\end{array}$ & $820 \mathrm{~mW} / \mathrm{m}^{2}$ & 49 \\
\hline Primary wastewater & Single-chamber MFC & Lactic acid & $\begin{array}{l}\text { Graphite fiber brushes-anode } \\
\text { Carbon cloth-cathode }\end{array}$ & $739 \mathrm{~mW} / \mathrm{m}^{2}$ & 49 \\
\hline Primary wastewater & Single-chamber MFC & Succinic acid & $\begin{array}{l}\text { Graphite fiber brushes-anode } \\
\text { Carbon cloth-cathode }\end{array}$ & $444 \mathrm{~mW} / \mathrm{m}^{2}$ & 49 \\
\hline
\end{tabular}


Note: $\quad{ }^{1} \mathrm{POME}=$ Palm Oil Mill Effluent

Units of surface power density are given in milliwatts per square meter, volume power density in watts per cubic meter, and units of voltage in millivolts. 
Table 3. Performance of microbial fuel cells for wastewater treatment

\section{Wastewater}

Swine wastewater

Starch processing

wastewater

Real urban wastewater

Olive mill wastewaters

Protein-rich wastewater

Paper recycling

wastewater

\section{Cassava mill}

wastewater

Food processing

wastewater

Domestic wastewater

Chocolate industry

wastewater

Biodiesel wastes

Beer brewery wastewater

Brewery wastewater

Potato Processing

wastewater

\section{Type of MFC}

Single-chamber MFC

Single-chamber MFC

Double-chamber MFC

Single-chamber MFC

Double-chamber MFC

Single-chamber MFC

Double-chamber MFC

Double-chamber MFC

Double-chamber MFC

Double-chamber MFC

Single-chamber MFC

Single-chamber MFC

Single-chamber MFC

Tubular MFC

\section{Reference}

Graphite electrodes

Carbon cloth as electrodes

Graphite rods as electrodes

Graphite fibers-brush

Toray carbon paper as anode

carbon cloth as cathode

Carbon paper

Carbon cloth as electrodes

Graphite particles as anode

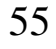

60

61

4

11 Graphite felt as cathode
73

74 
Palm oil mill effluent

Animal carcass wastewater

UML-MFCs

Up-flow tubular MFC

Double-chamber MFC
Double-chamber MFC
Graphite granules, Carbon fiber felt

Graphite felt as anode

Carbon cloth as cathode

Carbon felt

Graphite plates
Food waste leachate

Chemical wastewater 
Table 4. Performance of microbial fuel cells for bioremediation

\begin{tabular}{|c|c|c|c|c|c|}
\hline Heavy metals/ Wastewater & Type of MFC & Electrode material & $\%$ Removal & Power density & Reference \\
\hline Chromium (VI) & Double-chamber MFC & $\begin{array}{l}\text { Graphite granules-cathode } \\
\text { Graphite brush-anode }\end{array}$ & 94 & $6.4 \mathrm{~W} / \mathrm{m}^{3}$ & 85 \\
\hline Chromium (VI) & Double-chamber MFC & Carbon fiber felt & 76 & $970 \mathrm{~mW} / \mathrm{m}^{2}$ & 86 \\
\hline Sulfide & Double-chamber MFC & Carbon fiber felt & 85 & $572.4 \mathrm{~mW} / \mathrm{m}^{2}$ & 87 \\
\hline Cadmium & Single-chamber MFC & Carbon cloth & 90 & $3600 \mathrm{~mW} / \mathrm{m}^{2}$ & 88 \\
\hline Zinc & Single-chamber MFC & Carbon cloth & 97 & $3600 \mathrm{~mW} / \mathrm{m}^{2}$ & 88 \\
\hline Vanadium & Double-chamber MFC & Carbon fiber felt & 68 & $970 \mathrm{~mW} / \mathrm{m}^{2}$ & 89 \\
\hline Ammonia-copper (II) & Double-chamber MFC & $\begin{array}{l}\text { Graphite felt-anode } \\
\text { Graphite plate-cathode }\end{array}$ & 96 & $140 \mathrm{~mW} / \mathrm{m}^{2}$ & 90 \\
\hline Mercury $\left(\mathrm{Hg}^{2+}\right)$ & Double-chamber MFC & $\begin{array}{l}\text { Graphite felt-anode } \\
\text { Carbon felt- cathode }\end{array}$ & 99.5 & $433 \mathrm{~mW} / \mathrm{m}^{2}$ & 91 \\
\hline Azo dye Congo red & Single-chamber MFC & Carbon brush & 98.3 & - & 92 \\
\hline Cyanide & Double-chamber MFC & Carbon cloth & 88.3 & - & 93 \\
\hline Copper $\left(\mathrm{Cu}^{2+}\right)$ & Double-chamber MFC & Graphite felt electrodes & 99.5 & $319 \mathrm{~mW} / \mathrm{m}^{2}$ & 106 \\
\hline Chromium (VI) & Single-chamber MFC & $\begin{array}{l}\text { Carbon brush-anode } \\
\text { Carbon cloth-cathode }\end{array}$ & 99 & $419 \mathrm{~mW} / \mathrm{m}^{2}$ & 107 \\
\hline Nitrate & Single-chamber MFC & Graphite rods & 30 & $3900 \mathrm{~mW} / \mathrm{m}^{3}$ & 108 \\
\hline Nitrite & Single-chamber MFC & Graphite rods & 37 & $3600 \mathrm{~mW} / \mathrm{m}^{3}$ & 108 \\
\hline
\end{tabular}

Note: Units of surface power density are given in milliwatts per square meter; volume power density in watts per cubic meter. 


\section{List of figures}

1. Number of publications in the last five years, showing an increase in interest of MFC technology among researchers. (a) The number of publications (original research articles/review articles) on MFCs from the year 2011 to 2017. The data is based on the number of articles mentioning 'microbial fuel cell' in Scopus till April 24, 2017. (b) The chart reveals a steep increase of interest in MFC research, reflected by an abrupt rise in the number of publications in the years from 2011 to 2017 as compared to the past years between 1980 and 2010. (c) The pie chart shows the countrywise distribution in MFC research, the top 20 countries with respect to the number of articles published in MFC research field. The data is based on the number of articles mentioning 'microbial fuel cell' in Scopus till April 24, 2017.

2. General principle of a double chamber microbial fuel cell and the applications based on the MFC compartment.

3. Molecular Machinery for Extracellular Electron transfer mechanisms. Schematic image of the proposed EET of two metal respiring bacteria and their interactions with an electrode in a bioelectrochemical system. Dashed arrows indicate hypothetical electron flow and solid arrows indicate experimental proved electron flow. (A) Branched outer membrane cytochromes (OMCs) system of Geobacter sulfurreducens. Electrons can be transported between inner membrane, periplasm, outer membrane, and an electrode via a chain of cytochromes and menaquinones (MQ). Terminal OMCs can vary depending on the environmental conditions. (B) Unique Mtr-pathway and terminal reductases of Shewanella oneidensis. Quinones (Q) pass electrons to CymA or TorC, which transfer the electrons to terminal reductases or an MtrCAB complex. MtrCAB complex can interact with the electrode direct or via flavin molecules (FL). The figure is designed by Ms. Helena Reiswich and is a reproduction from [37], with permission from the publisher and the corresponding author.

4. Gastronome"-A prototype MFC powered robot [63].

5. EcoBot II fully assembled with the wireless transmitter and temperature sensor on top [64].

6. (a) Block diagram of the telemetry system powered by the microbial fuel cell. (b) A sensor and a telemetry system powered by a microbial fuel cell [65].

7. Example 7-day time record of meteorological data transmitted from first generation BMFC-powered buoy [66].

8. (a) Pee power field trial in Glastonbury Music Festival, June 2015; (b) urinal assembly and MFC stack arranged in 12 modules [79].

9. Schematic diagram of the $90 \mathrm{~L}$ stackable baffled microbial fuel cell [82].

10. (a) Schematic diagram of an MFC. (b) Mechanism for MFC-based BOD monitoring. Increased BOD input provides more organic matter/fuel for the MFC, which in turn results in an increase in current output. (c) Mechanism for MFC-based toxicity monitoring. Increased toxin input will repress/inhibit the cell viability/metabolic activity, which directly reduces the current output [94]. 
11. Voltage responses of MFC-based biosensors to different samples. The figure shows the performance of four MFCs used to sense the addition of three samples (with different concentrations) in the anode chamber, resulting five shocks (a) to (e). (a) The MFC was injected with iron (non-toxic metal) of concentration $48 \mathrm{mg} / \mathrm{L}$ after 150 minutes of operation. The injection suddenly decreased the voltage from $121 \mathrm{mV}$ to $67 \mathrm{mV}$. (b) The MFC was injected with chromium (acute toxin) of concentration $1 \mathrm{mg} / \mathrm{L}$ after 74 minutes of operation. After 134 minutes of the first fall (shock), the voltage decreased from the steady point (89 $\mathrm{mV}$ ) to $81 \mathrm{mV}$. (c) After 74 minutes of operation, there was a steep fall in the voltage from $109 \mathrm{mV}$ to $91 \mathrm{mV}$. (d) In another MFC, iron of concentration $1 \mathrm{mg} / \mathrm{L}$ was injected in the anode chamber after 30 minutes of operation. This low concentration decreased the voltage slightly from $121 \mathrm{mV}$ to $118 \mathrm{mV}$, though higher concentration sharply decreased the voltage as mentioned earlier in (a). (e) The effect of carbon substrate was also sensed in the MFC, addition of $200 \mathrm{mg} / \mathrm{L}$ sodium acetate showed instant rise in the voltage from $102 \mathrm{mV}$ to 114 $\mathrm{mV}$ after 2 minutes, which further increased to $122 \mathrm{mV}$ after 4 minutes.

12. (a) The MFC array used for $\mathrm{Cu}^{2+}$ toxicity monitoring, (b) acidic toxicity monitoring [100].

13. The signal interference of an MFC sensor by the combined shock of biochemical oxygen demand (BOD) and toxicity in a continuous flow-through mode: (a) the MFC sensor operated with background acetate of $0.3 \mathrm{mM}$; (b) the MFC sensor operated with background acetate of $5 \mathrm{mM}$ [103]. 
Figure 1.
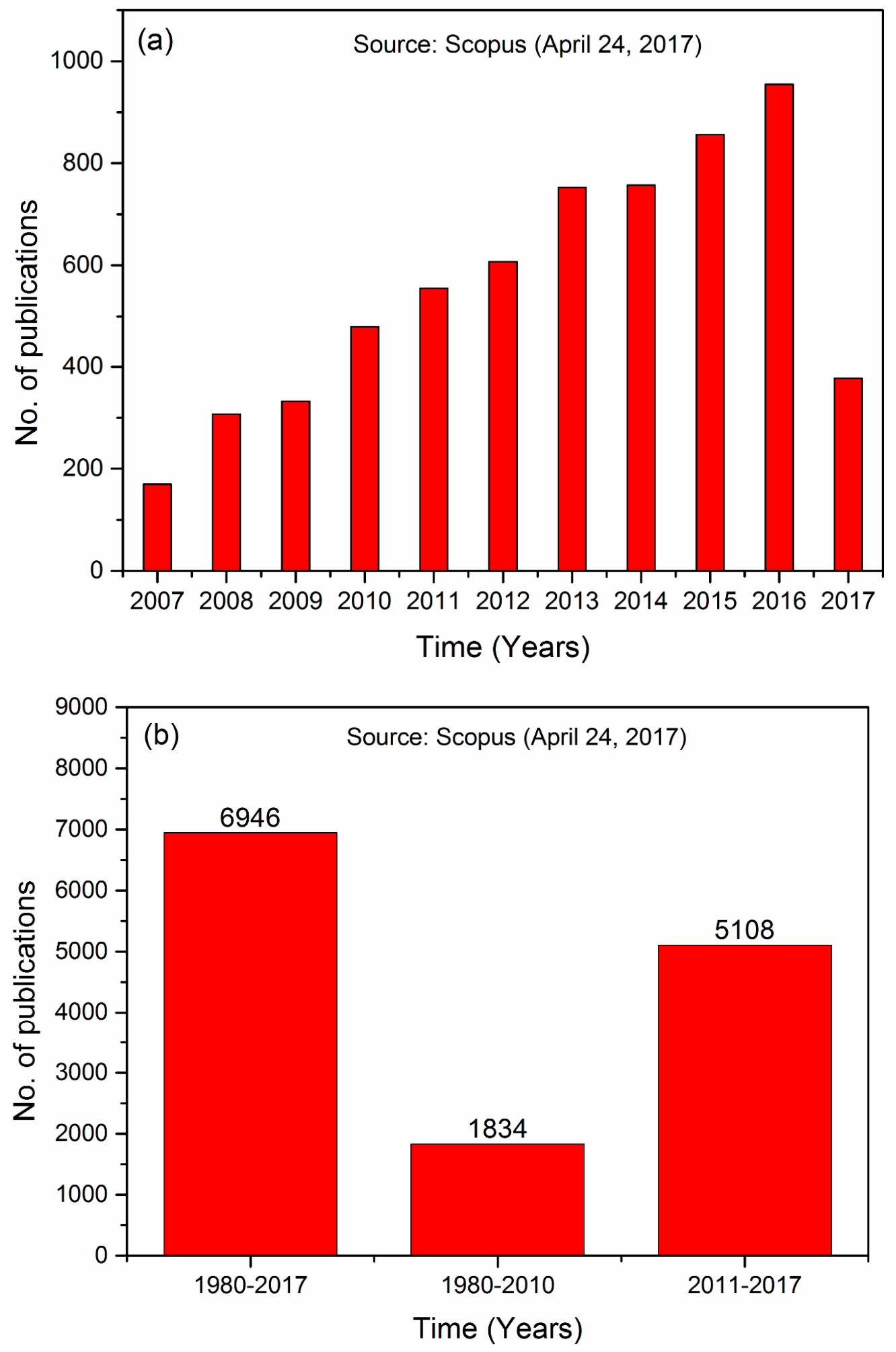
(c)

Source: Scopus (April 24, 2017)

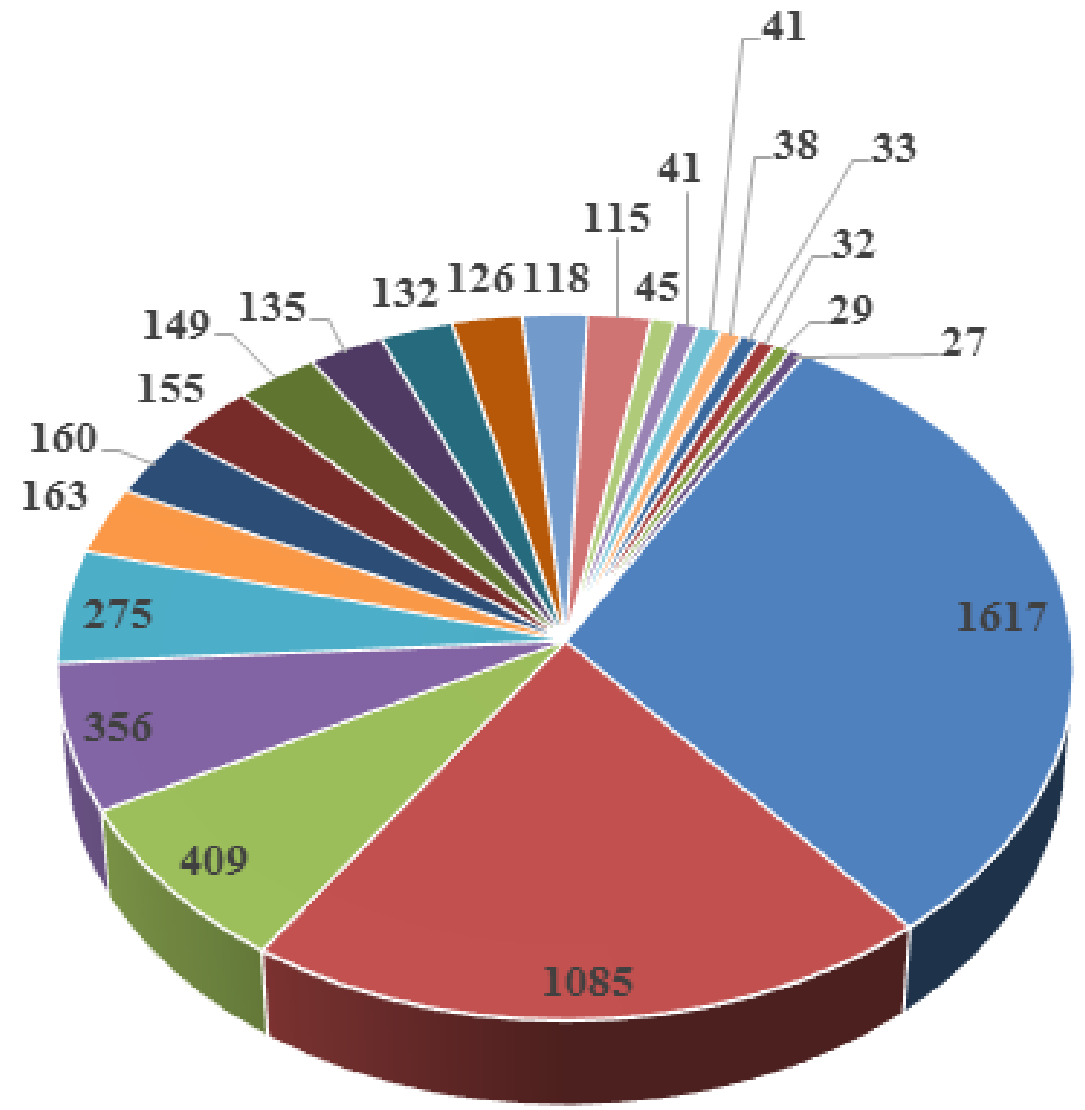

- China

- United States

- India

- South Korea

- United Kingdom

- Japan

- Italy

- Spain

- Germany

- T aiwan

- Malaysia

- Canada

- France

- Iran

- Brazil

- Poland

- Turkey 
Figure 2.

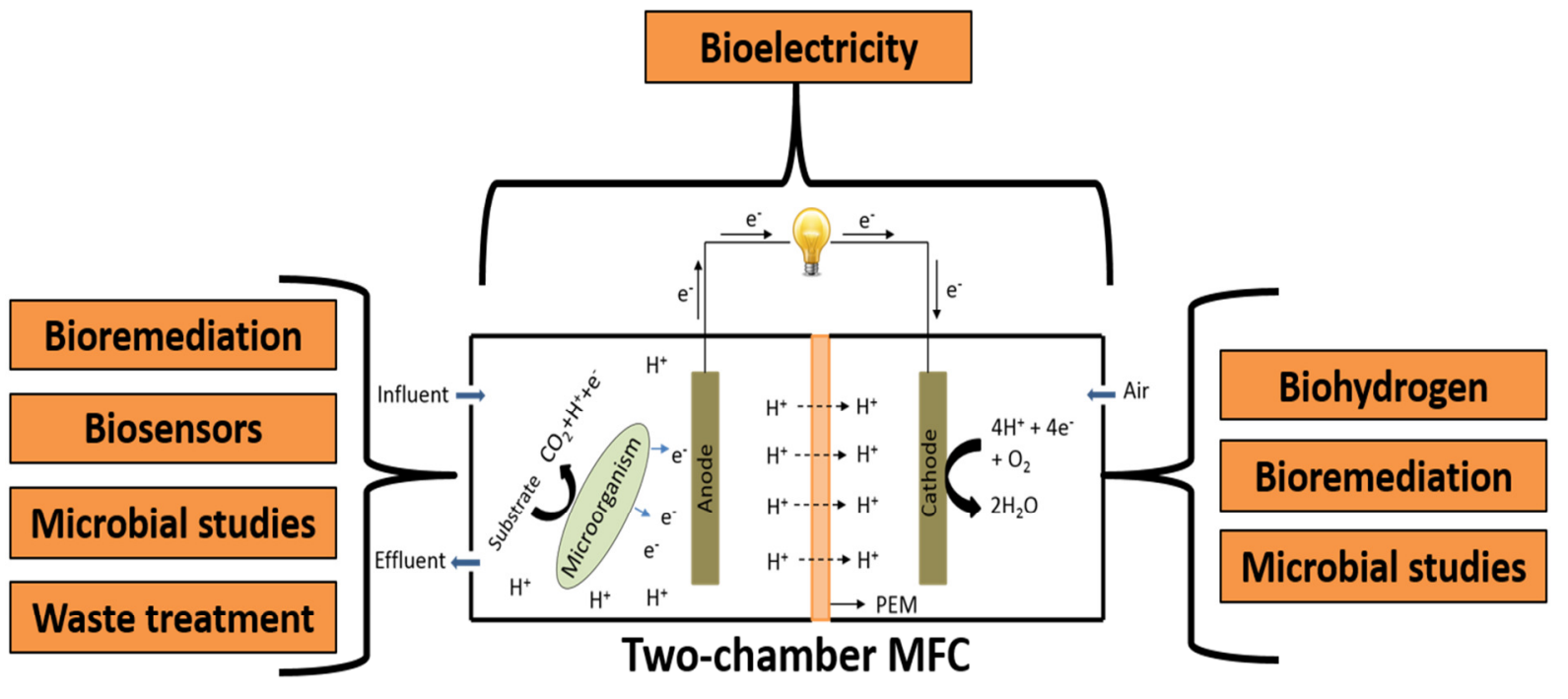




\section{Figure 3.}
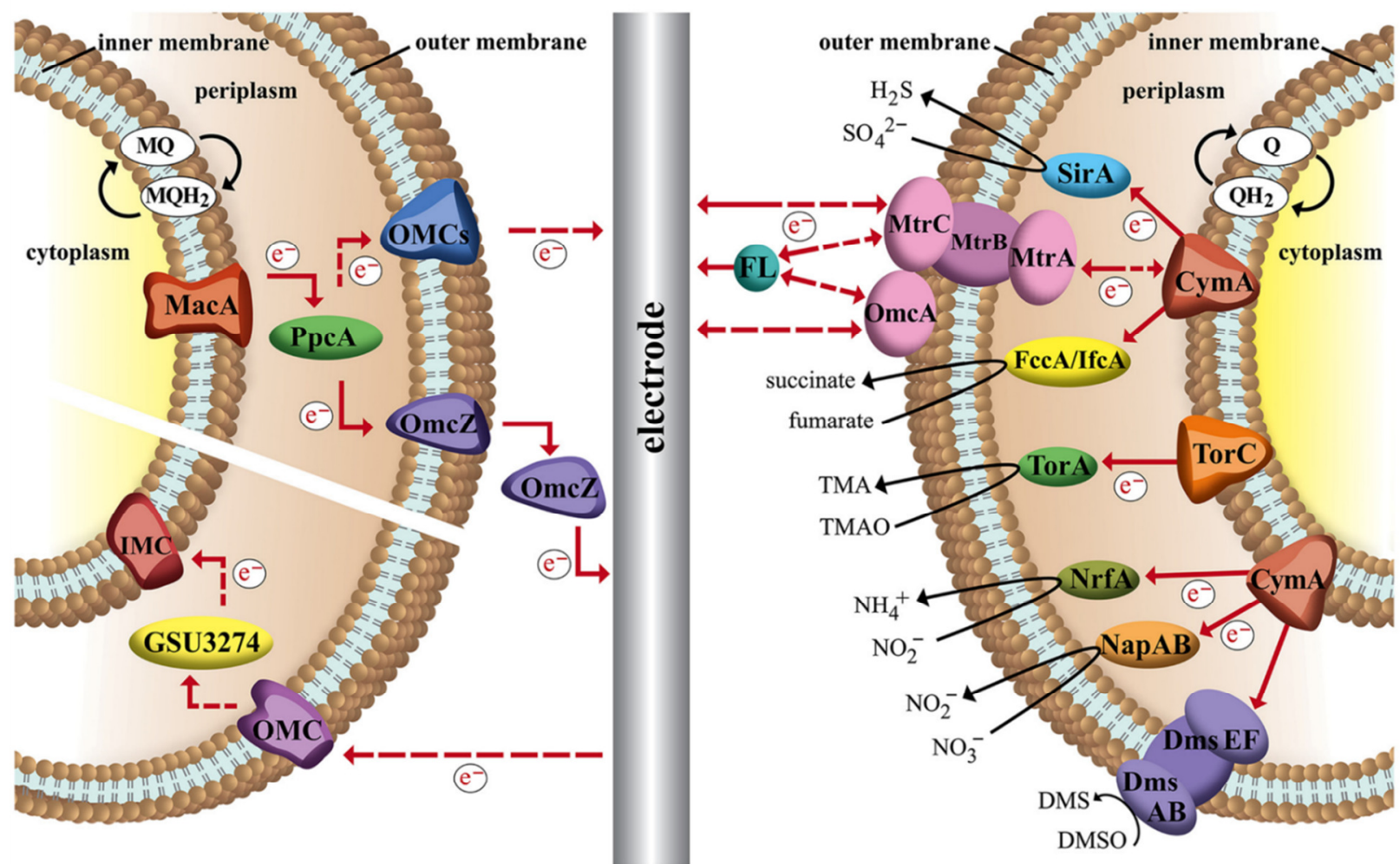
Figure 4.

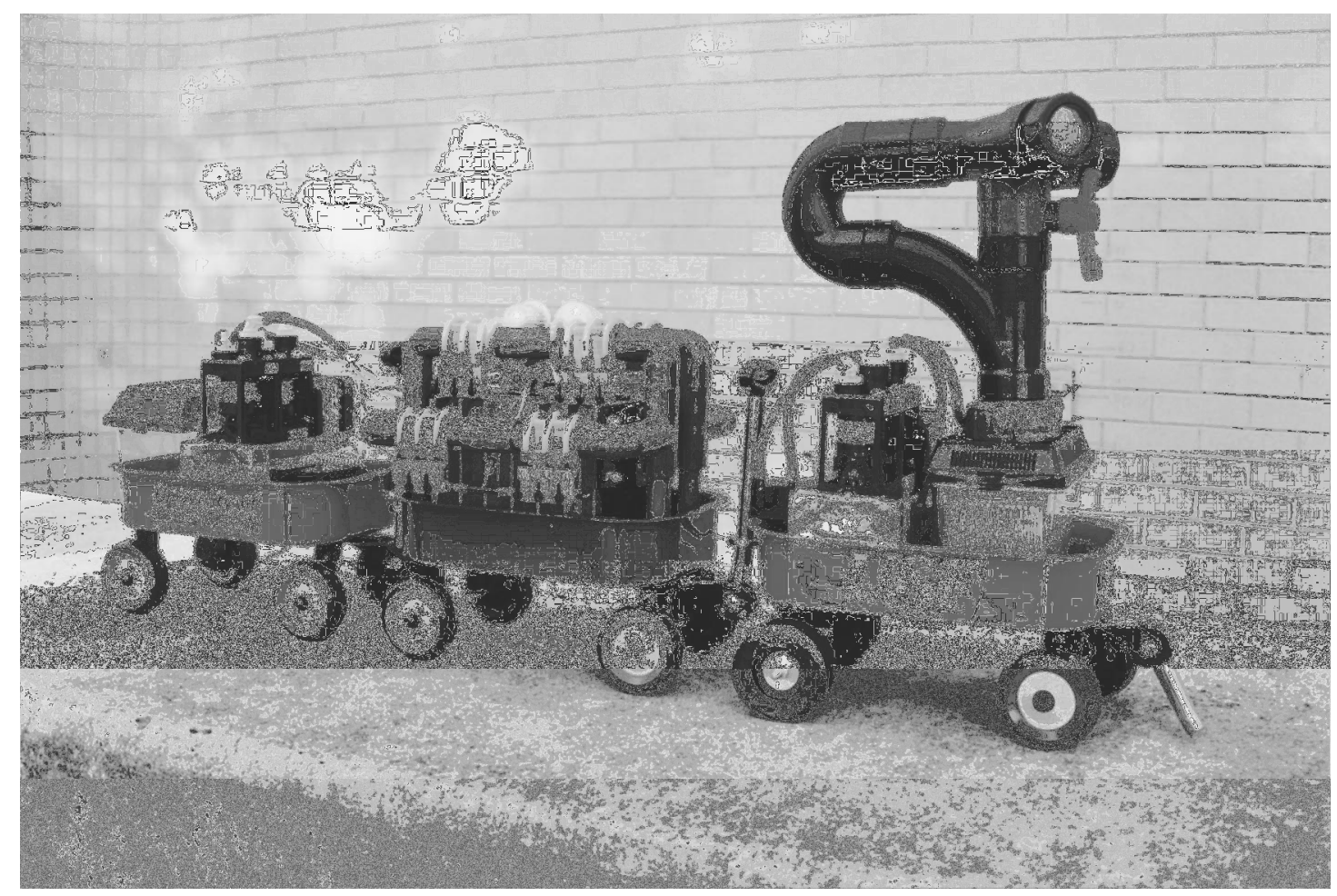


Figure 5.

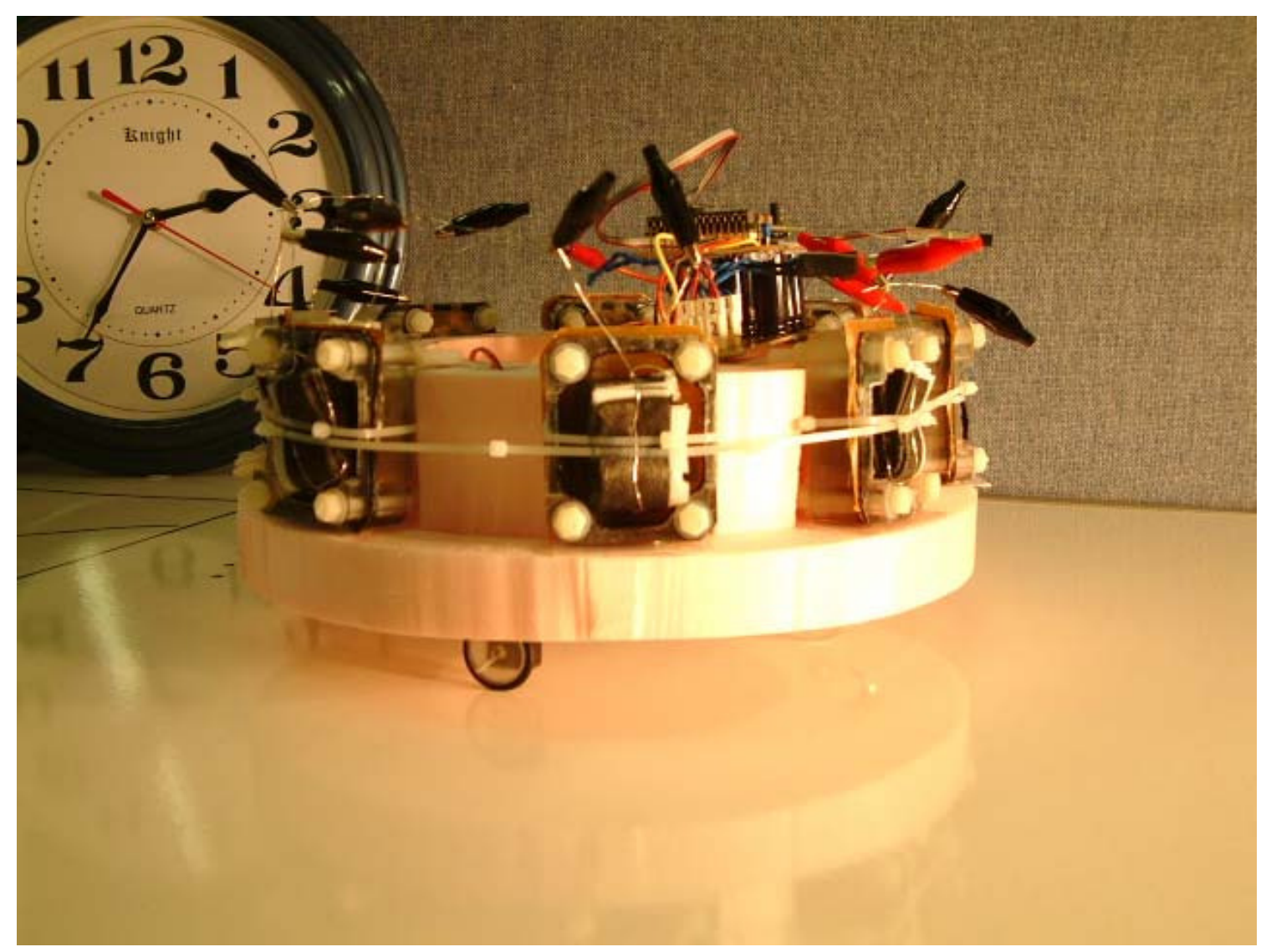


Figure 6.

(a)

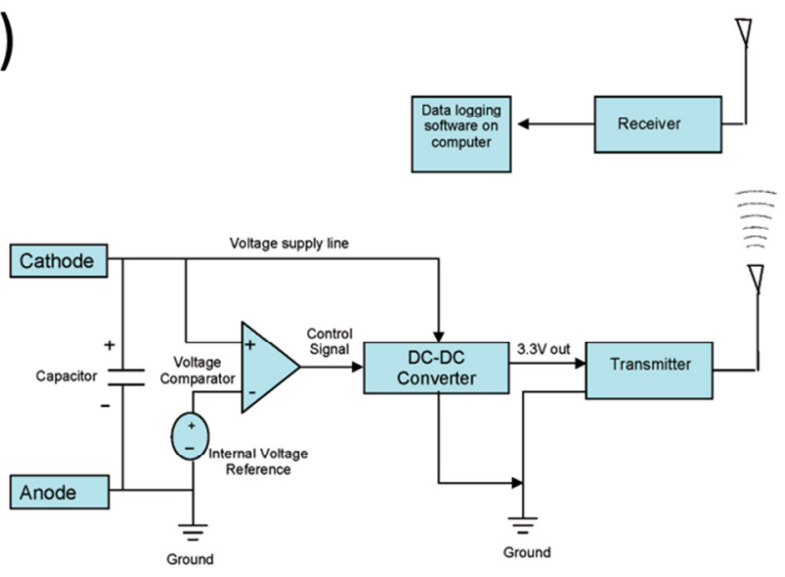

(b)

Microbial deposition By $\mathrm{MOB}_{2 \mathrm{e}}$; $\mathrm{Mn}^{2+}$. Cathode $\mathrm{MnO}_{2}=\mathrm{MnOOH}$.

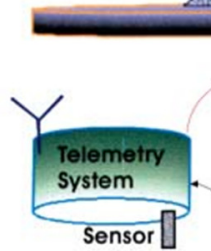

Anode $\mathrm{Mg} \rightarrow \mathrm{Mg}^{2+}+2 \mathrm{e}$ 
Figure 7.
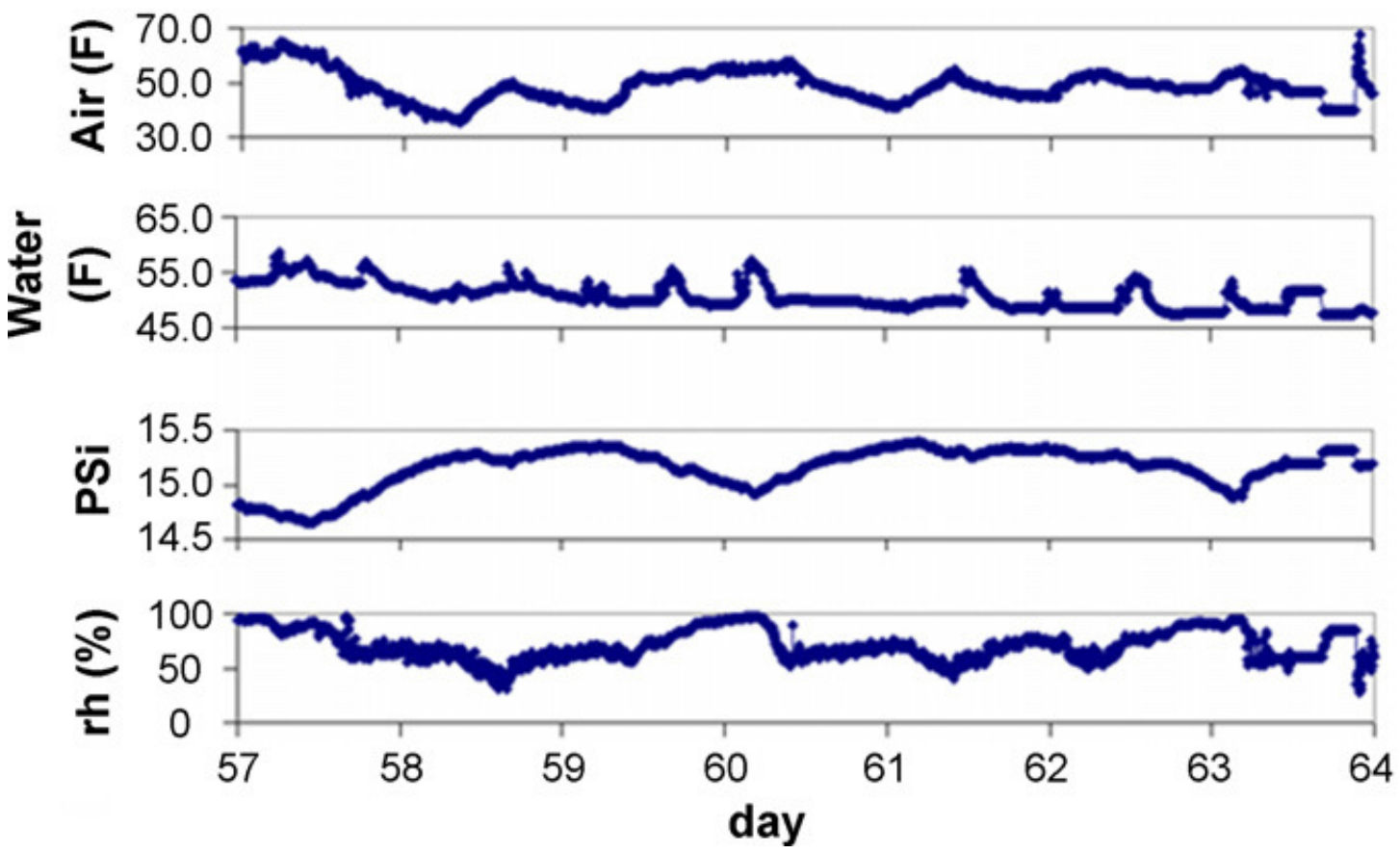
Figure 8.

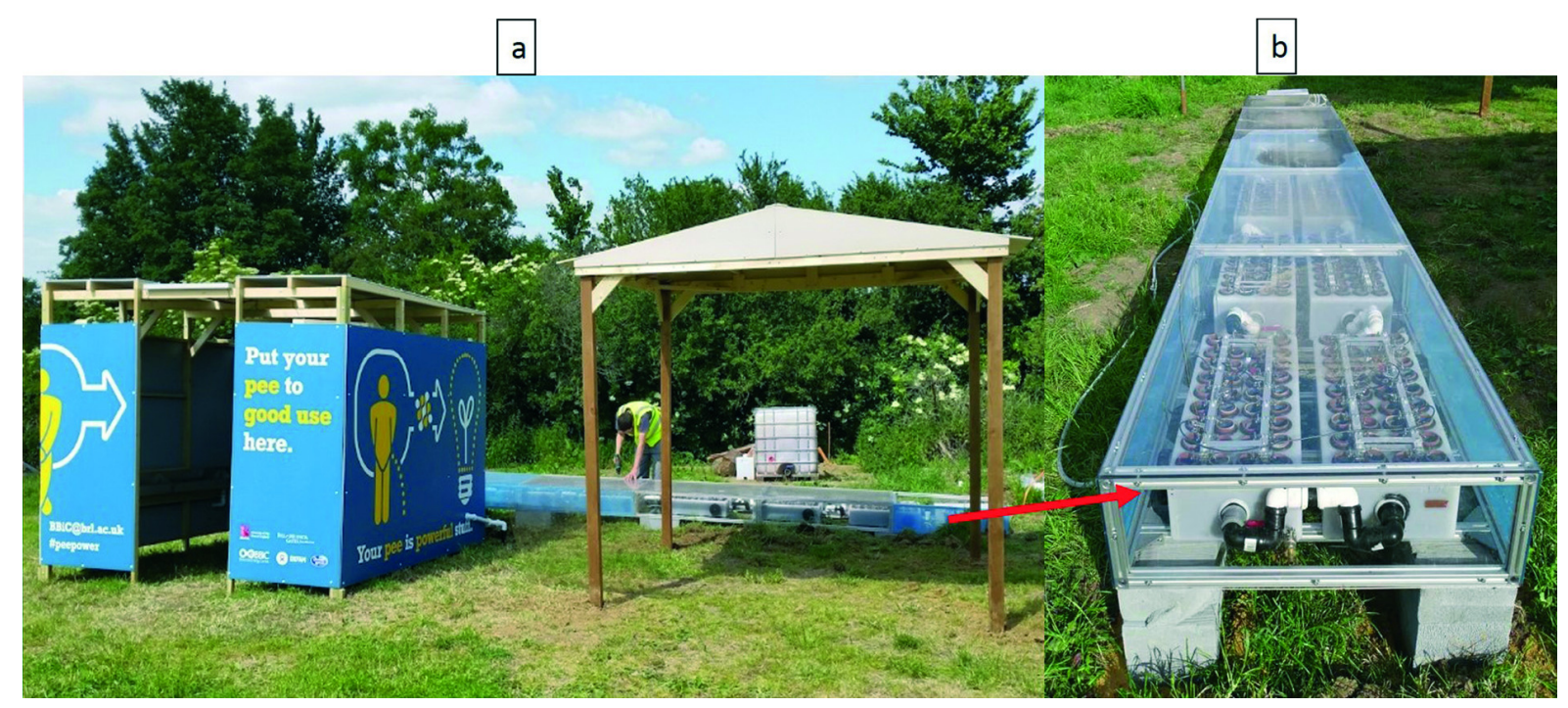


Figure 9.

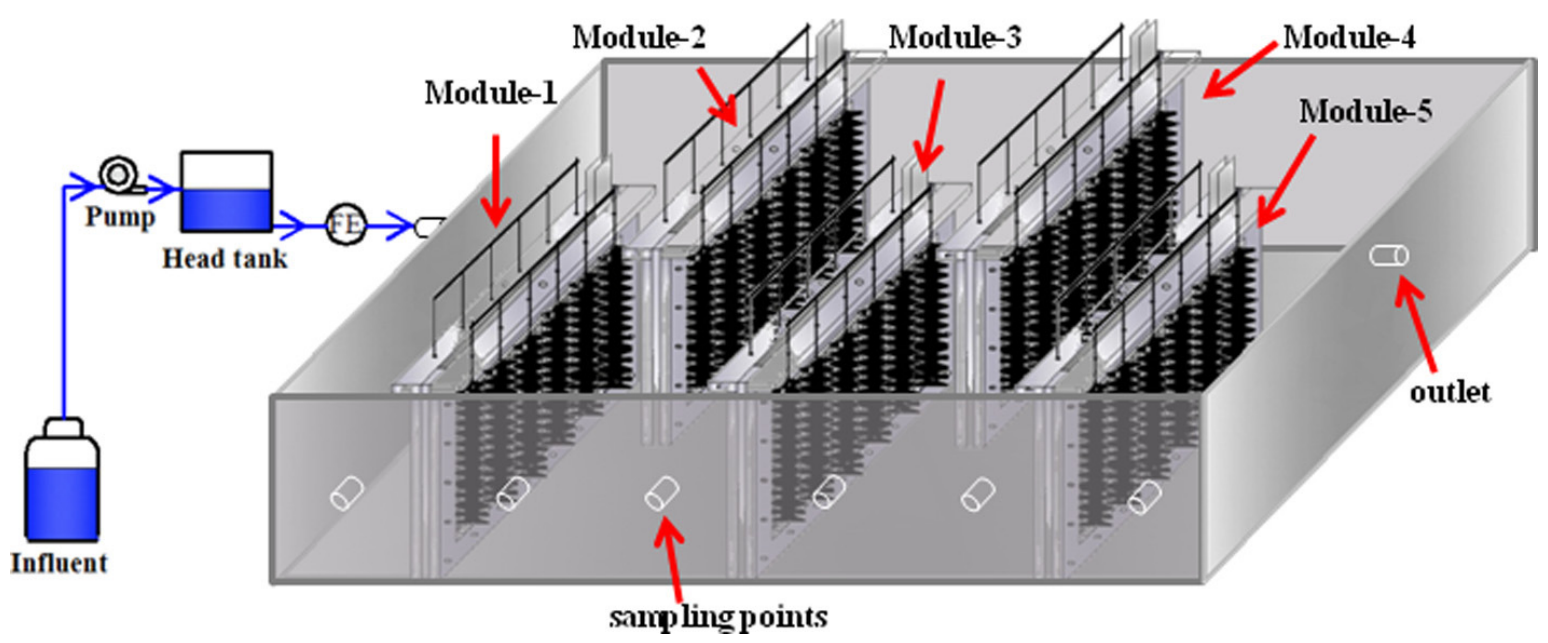


Figure 10.

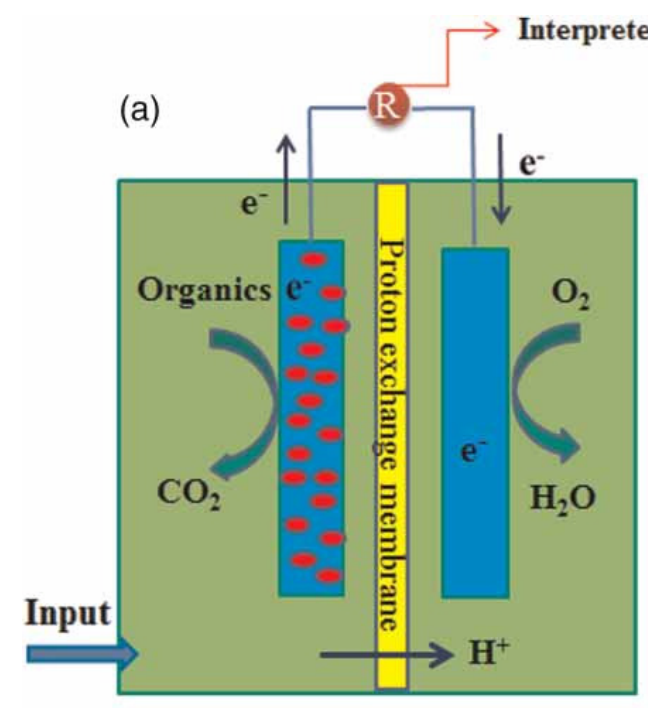

Anode compartment Cathode compartment (anaerobic) (aerobic) (b)

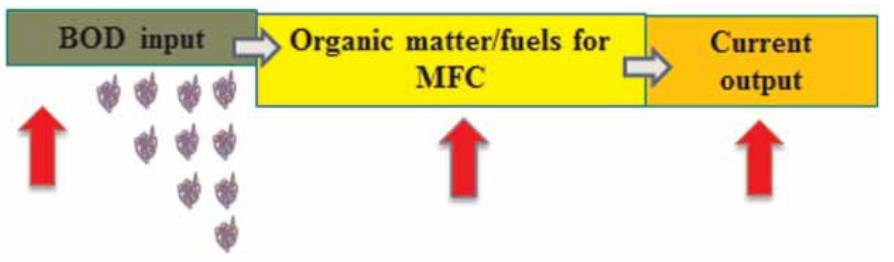

(c)

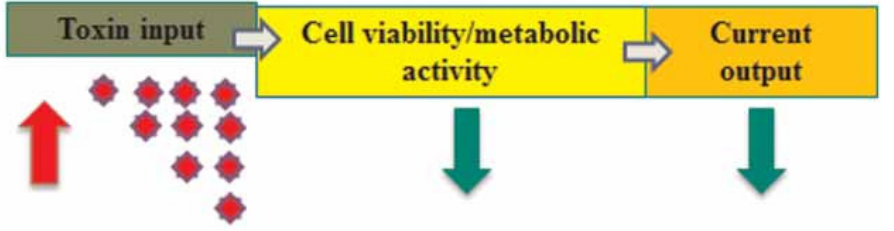

Organic matter Toxin Increase Decline 
Figure 11.

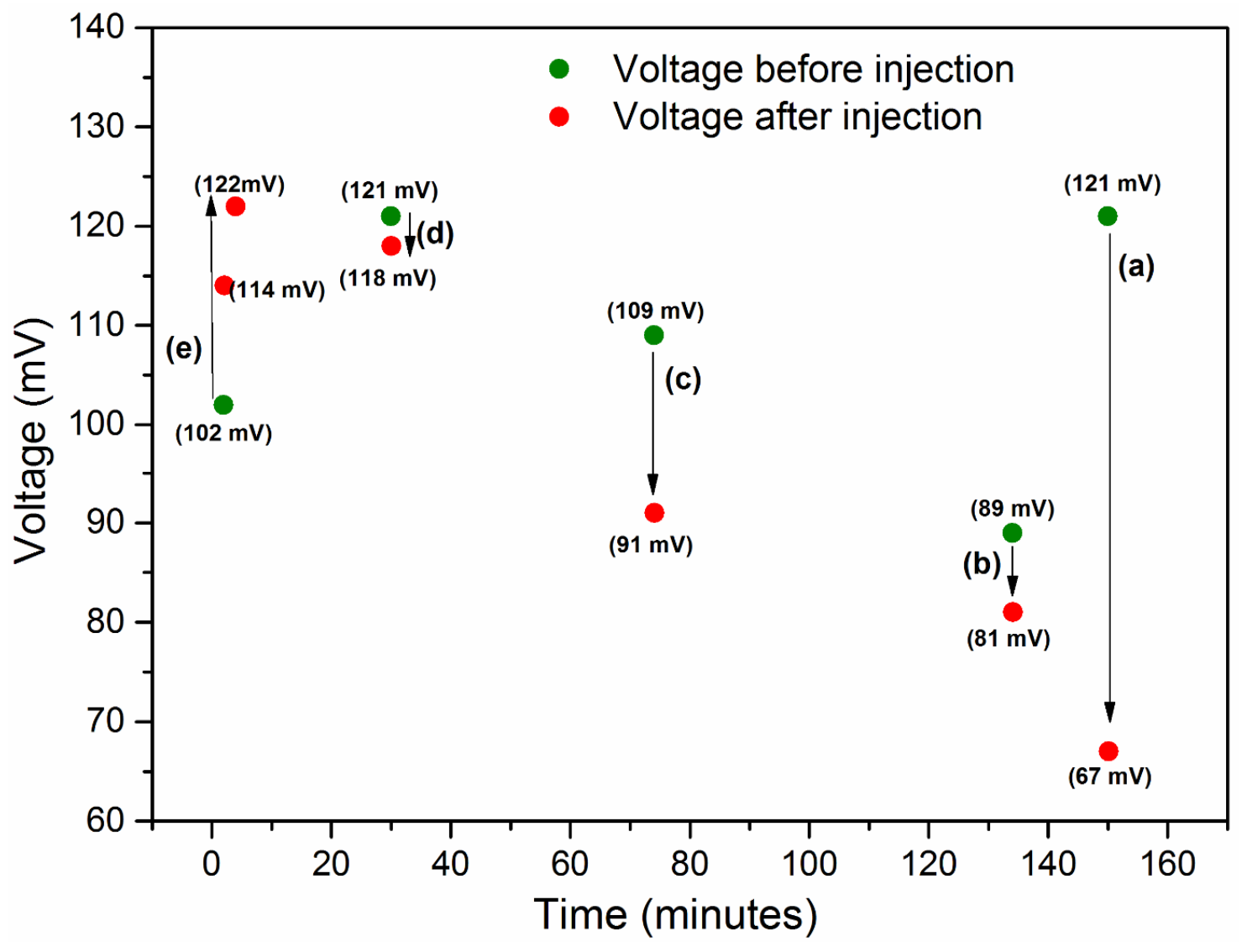


Figure 12.

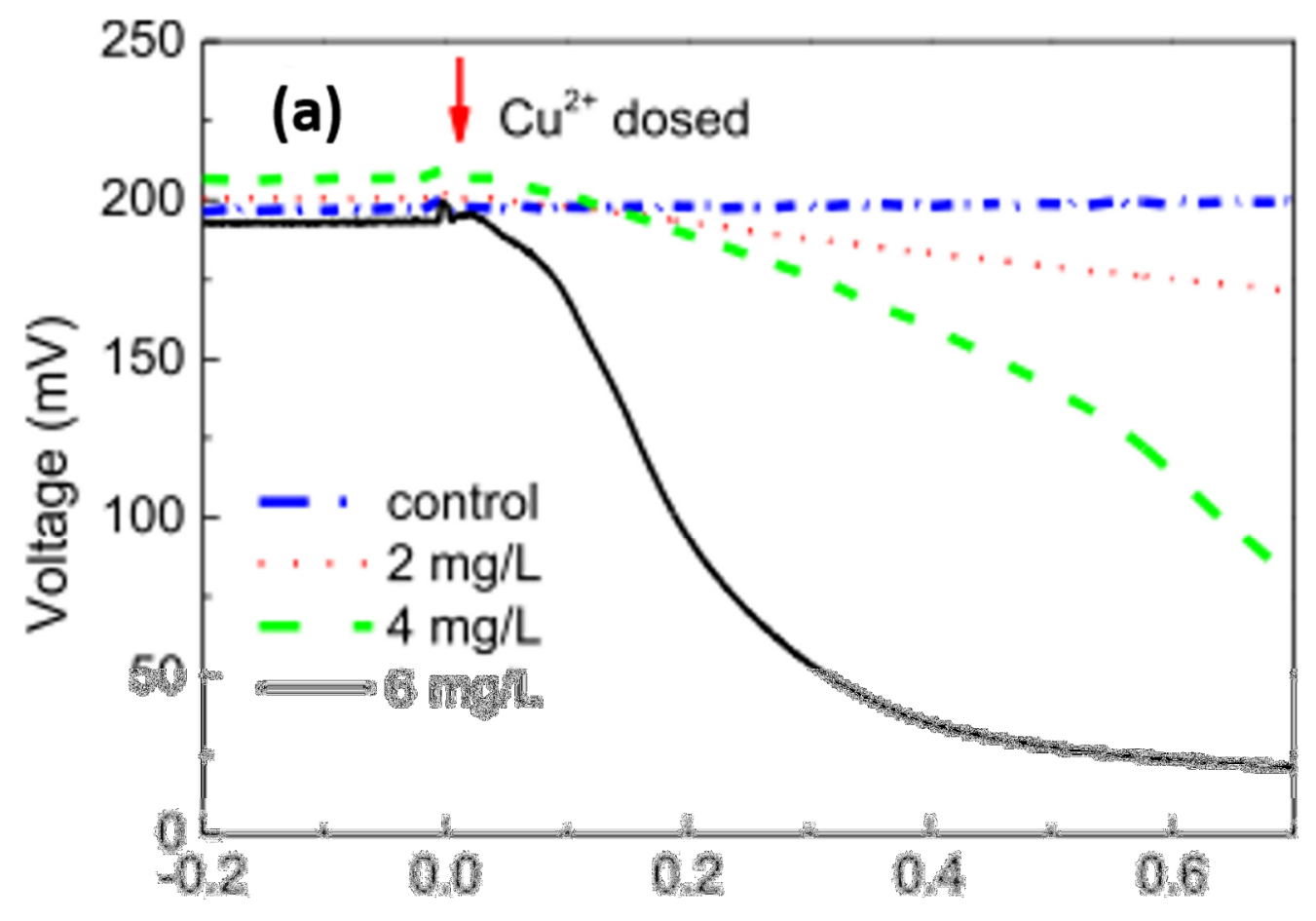

Time (h)

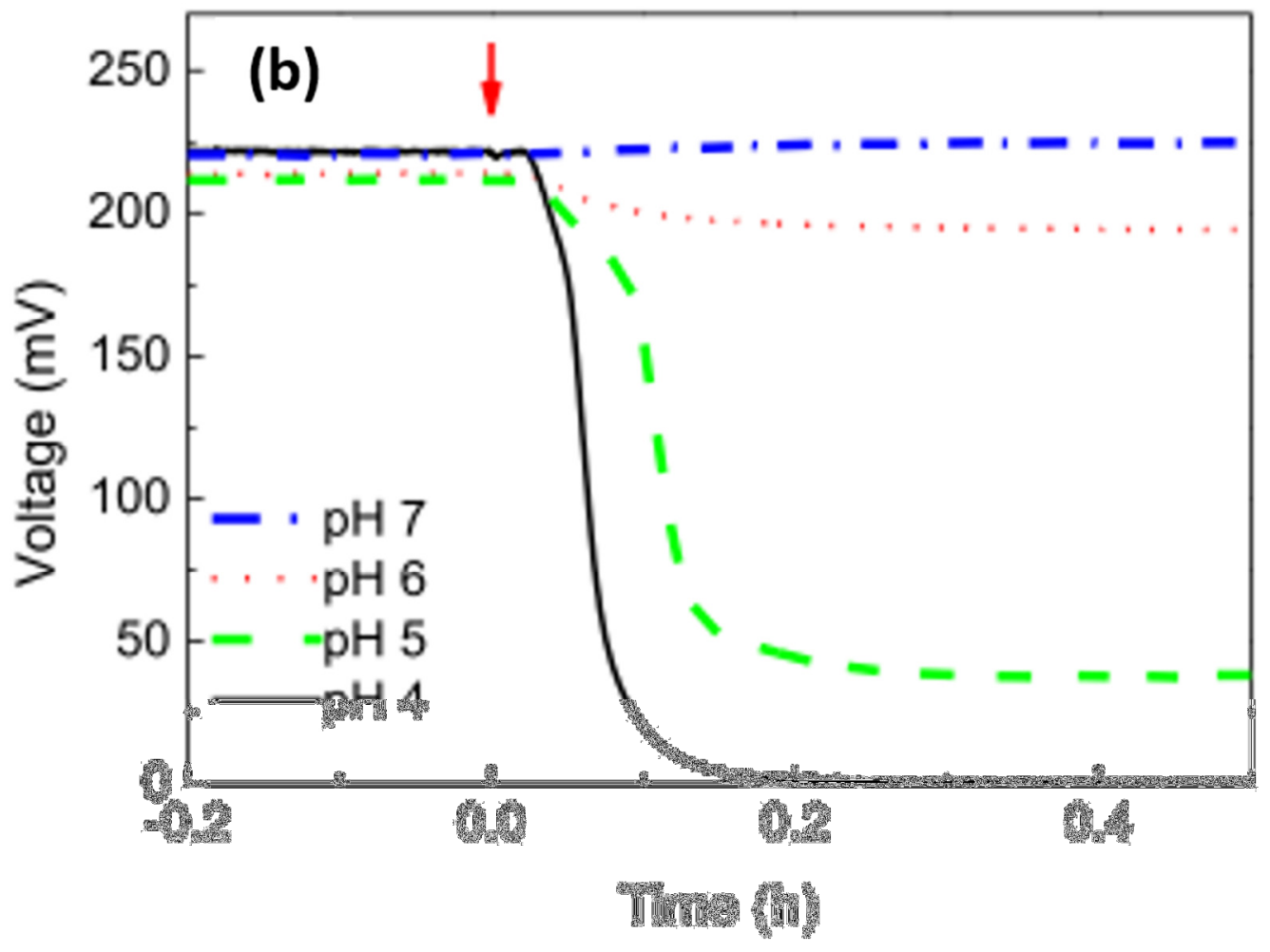


Figure 13.
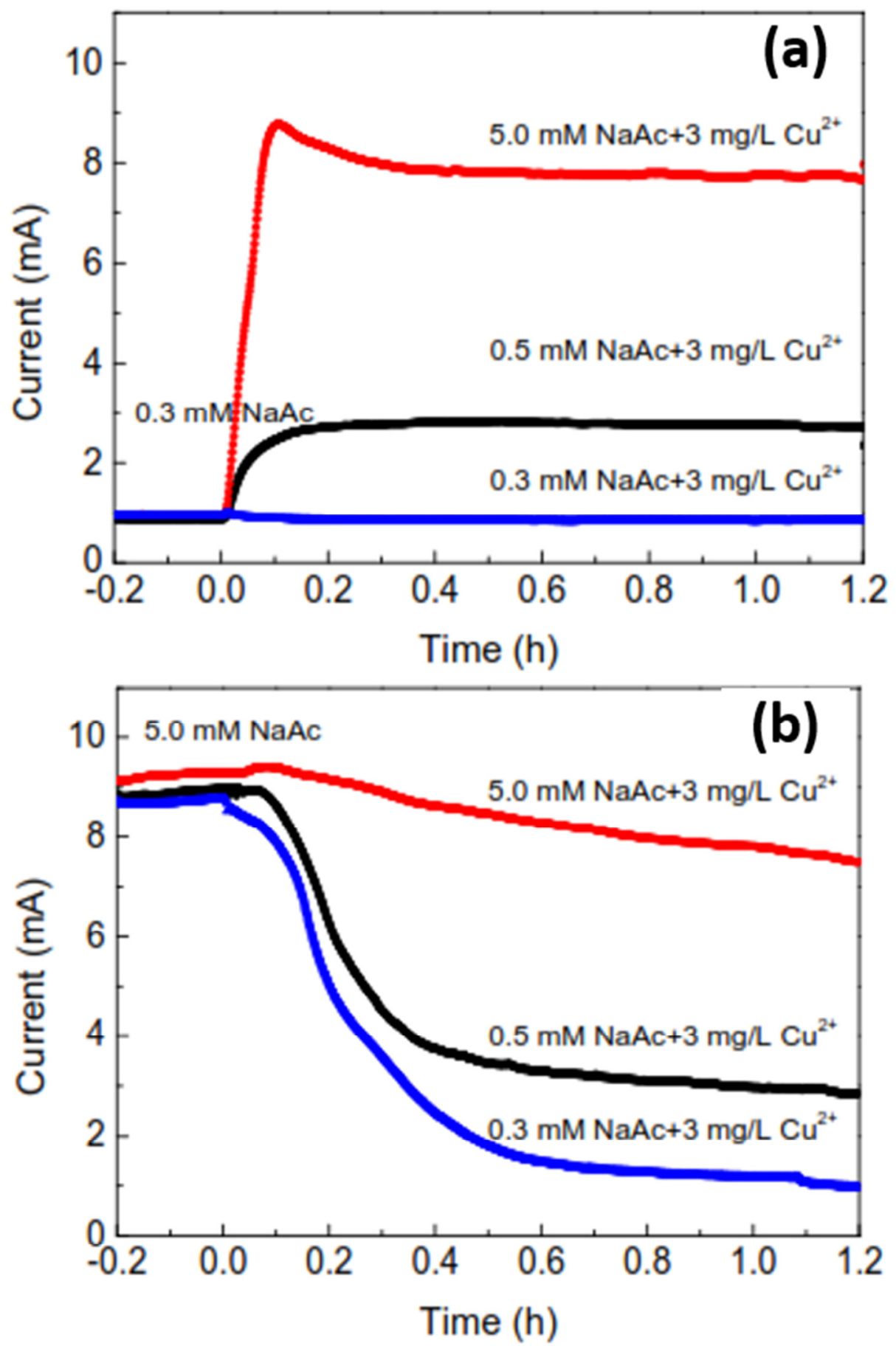